(Aus dem Pathologischen Institut der. Universität Bern

[Direktor: Prof. Dr. C. Wegelin].)

\title{
Über Eiseninkrustation der Bindegewebssubstanzen bei Hämochromatose und bei lokalen Blutungen.
}

\author{
Von \\ Dr. Heinrich Schappisser, \\ I. Assistent.
}

Mit 3 Textabbildungen.

(Eingegangen am 13. April 1922.)

Die vorliegende Arbeit soll über eine eigenartige Ablagerung von Kalk und Eisen in Lymphdrüsen bei einem Falle von allgemeiner Hämochromatose berichten sowie über seltene Formen der Eisenablagerung in strumösen Schilddrüsen und in der Milz bei einem Falle von Lymphogranulom. Die bis jetzt über Eisenablagerungen vorliegenden Arbeiten berücksichtigen fast ausschließlich das bei. Verkalkungsprozessen gefundene Eisen, während über unabhängig von Kalk vorgefundene Fisenablagerungen nur ganz fragmentarische Mitteilungen vorliegen. Ich möchte deshalb das Hauptgewicht bei meinen Untersuchungen auf das. Studium der reinen Eisenablagerung legen.

Über das gleichzeitige Vorkommen von Kalk und Eisen und ihre gegenseitige Beziehung sind die Untersuchungsergebnisse und Ansichten der Autoren zum Teil noch sehr verschieden. Namentlich bildet der Eisengehalt bei Verknöcherungsprozessen und die ihm beizumessende Bedeutung noch eine offene Streitfrage. Gierke fand nämlich als erster an den Knochen von menschlichen Föten und Neugeborenen einen konstanten Eisengehalt, und zwar ausschließlich oder doch am stärksten an den jüngsten Knochenbälkchen. Schmorls Untersuchungen bestätigten diese Befunde. Zudem ergaben ihm pathologische Knochenneubildungsprozesse beim Erwachsenen, z. B. Callusbildungen, Osteophyten, rachitische Knochenneubildungen usw. positive Eisenreaktion. Er miBt deshalb dem Eisen bei der Knochenbildung eine große physiologische Bedeutung zu, indem er glaubt, daß die Imprägnation des zunächst kalklos angebildeten Knochens mit Eisensalzen gleichsam die Beize für die nachherige Ablagerung von Kalksalzen darstellt. Auch Best und Orth erhielten positive Eisenreaktion, letzterer will aber dem Eisen keine weitere Bedeutung zuerkennen, sondern glaubt, daß es von Blutungen herstamme (Schenkelhalsfraktur).

Hueck stellte ebenfalls auf diesem Gebiet ausgedehnte Untersuchungen an, und ihm gebührt das Verdienst, als erster auf die große Gefahr einer künstlichen Imbibition des Kalkes mit Eisen hingewiesen zu haben, wie sie durch Berührung mit nicht absolut eisenfreien Flüssigkeiten oder durch langes Stehen in Gläsern in 
den gewöhnlichen Fixierungsflüssigkeiten zustande kommt. Der Kalk ist nämlich sehr eisengierig, wie er überhaupt eine große Affinität zu Schwermetallen besitzt (Stoelzner). Hueck erhielt bei Einhaltung besonderer von ihm geforderten Vorsichtsmaßregeln zur Verhütung einer Verunreinigung des Kalkes mit Eisen nie eine positive Reaktion und stellte deshalb den Eisengehalt des physiologisch verkalkten Knochengewebes und der gewöhnlichen Formen der pathologischen Verkalkung in Abrede. Auch Noesske gelangt zu ganz ähnlichem Ergebnis. Spätere unter Innehaltung der von Hueck angegebenen Vorsichtsmaßregeln vorgenommene Untersuchungen führten wiederum zu versehiedenen Resultaten. Eliascheff findet den Knochen von menschlichen Föten und Neugeborenen konstant eisennegativ, hingegen rachitischen Knochen sehr oft eisenhaltig. Sumita hingegen kommt in einer ausgedehnten Untersuchungsreihe im wesentlichen zu einer Bestätigung der Befunde von Gierke und Schmorl. Er glaubt, die Bilder, welche der wirklich eisenhaltige, junge Knochen gibt, sịcher trennen zu können von solchen, die dureh bloße Affinität des Kalkes zu Eisen entstanden sind. Er hält die Schmorlsche Auffassung von der großen physiologischen Bedeutung des Eisens bei Knochenbildungsprozessen für die richtige. Neuerdings gelangt Hueck nicht mehr zu einer so strengen Verneinung des Eisengehaltes bei Knochenbildungen. Er glaubt aber nicht, daß das Eisen ein unbedingt notwendiges Erfordernis für die nachfolgende Kalkablagerung darstellt. Der Befund von Eisen scheint ihm vielmehr ein zufälliger, denn die Verkalkung fötaler Gewebe beruht nach seiner späteren Ansicht auf einer Affinität der Gewebskolloide zu den elektropositiven Ca-Ionen, dieselbe Affinität scheinen sie nun teilweise auch zu den elektropositiven Eisenionen zu besitzen. Zudem wird ja der junge Knochen bald eisenhaltig, bald eisenfrei vorgefunden. Das abschließende Urteil über das Vorkommen und die Bedeutung des Eisens bei der Knochenbildung ist also noch keineswegs gesprochen.

Neben Knochen wurden auch sehr zahlreiche pathologische Verkalkungen von vielen Autoren auf ihren Eisengehalt geprüft. Hier sind die Ergebnisse noch inkonstanter, ebenso wechselt die Auffassung über die Bedeutung des Eisengehaltes bei den verschiedenen Autoren. So berichtet Kockel als erster über eisenhaltige und verkalkte elastische Fasern in den Gefäßwänden der Lunge in einem Falle von perniziöser Anämie und in Stauungslungen. Er sieht darin eine postmortale Imbibition des Kalkes mit eisenhaltigen Flüssigkeiten. Das gleiche fand Bittrolf in einer Stauungslunge. Er hält die Verkalkung der elastischen Fasern für das Primäre. Diese führt sekundär zu intravitaler Eisenaufnahme. Ehrlich berichtet über Eisenund Kalkimprägnation von elastischen Fasern, speziell in den elastischen Innenhätiten von Gehirn- und Schilddrüsenarterien, auch in alten Milzinfarkten. Er erhält den Eindruck, daß hier die Eisenimprägnation einer Kalkablagerung vorangeht, und glaubt an einen kausalen. Zusammenhang im Sinne Schmorls. Gierke findet z. B. die Sandkörper der Adergeflechte konstant eisenhaltig. Eine Aufzählung aller übrigen Befunde würde zu weit führen. In den meisten Fällen wird die Herkunft des Eisens auf Blutungen zurückgeführt oder auf sonstige Durchtränkung mit eisenhaltigen Flüssigkeiten. Ein besonderer biologischer Zusammenhang von pathologischen Verkalkungen und Eisenablagerungen wird außer von Ehrlich von keinem Autor angenommen.

Wir lassen hier unsere Untersuchungen folgen. Der erste Fall steht in Beziehung zur Kalkeisenfrage, während die übrigen reine Eisenablagerungen betreffen.

\section{Fall 1: Bronzediabetes mit allgemeiner Hämochromatose.}

Die Veränderungen, die wir hier beschreiben wollen, fanden sich in den retroperitonealen Lymphdrüsen bei einem unter dem Sympto- 
menbild des Bronzediabetes verstorbenen Manne. Durch die Sektion konnte die Diagnose bestätigt werden. Es fand sich eine ausgesprochene Oirrhose der Leber und des Pankreas und eine Hämochromatose der Leber, des Pankreas, der Nieren, des Magens, der Glandulae submaxillares, der Schilddrüse, der Haut, der retroperitonealen Drïsen und der Herz- und Skelettmuskulatur. Die Reichhaltigkeit der makroskopischen und mikroskopischen Befunde des Falles läßt uns eine Veröffentlichung derselben zweckmäßig erscheinen, besonders da das über Hämochromatose publizierte Material noch kein allzu großes und die Genese der Krankheit immer noch nicht vollkommen abgeklärt ist. Auf den Charakter der Pigmente und das Wesen der Krankheit wollen wir aber in dieser Arbeit nicht genauer eingehen, sondern nur die uns interessierenden Veränderungen in den Lymphdrüsen näher besprechen.

Die Krankengeschichte des Falles, die ich Herrn Prof. Kottmann verdanke, ist kurz gefaßt folgende:

Sehr kräftig gebauter Mann, vor 30 Jahren Lues, starker Potator. IBt seit ca. 10 Jahren auffallend wenig. Pat. bekam bei Einwirkung von Sonnenstrahlen immer sehr leicht eine stark pigmentierte Haut, die Haut des Gesichts und der Hände war denn auch immer stark braun pigmentiert (Autofahrer). Im August 1916 wurde erstmals eine Lebercirrhose konstatiert: Leber stark vergrößert, Leberrand 3 Querfinger ïber dem Nabel, Konsistenz sehr hart, kein Ascites, kein Ikterus. Allgemeinbefinden nicht gestört. Etwa $1 \mathrm{Jahr}$ vor dem Tode Verschlimmerung des Allgemeinbefindens, Pat. fühlt sich sehr matt. Im Urin jetzt $4 \%$ Zucker, zugleich fällt jetzt ein eigentümlich grauer, schmutziger Ton in der Pigmentierung von Kopf und Händen auf. Von jetzt ab auffallend rascher Kräfteverfall. Pat. leidet häufig an ausgedehnten Ekzemen. Auch jetzt nie Ascites oder Ikterus, Gallenfarbstoff im Urin negativ. Skleren rein weiß. Auf eine evtl. Pigmentierung der Mundscbleimhant wurde nicht geachtet. Der Zucker im Urin ging immer mehr zurück. Probe schließlich negativ. Blutuntersuchung nicht ausgeführt. Einige Wochen vor dem Tode Hautnekrosen nach Jodanstrich am linken Unterschenkel, in den letzten Tagen starke Abmagerung. Tod in somnolentem Zustande. Klinische Diagnose: Bronzediabetes.

Sektionsprotokoll: O,, Ph., 56jährig (Sektions-Nr. 152, 1919, Prof. Wegetin). Mittelgroßer, kräftig gebauter Körper, Thorax oben etwas flach, unten stark gewölbt. Panniculus mäßig. Muskulatur schwach. Keine Ödeme. Haut und Skleren ganz leicht ikterisch. Im Gesicht, an den Händen und Vorderarmen braungraue Pigmentierung der Haut, an den Armen vereinzelte, etwas abgeblaßte, punktförmige Blutungen. Am ganzen linken Unterschenkel von den Knöcheln bis zum Knie ist die Haut blaurot verfärbt. Epidermis dünn, glänzend, mit sehr zahlreichen großen Borken und weißlich glänzenden Schuppen bedeckt. Beim Einschneiden sind subcutanes Gewebe und Muskulatur des Unterschenkels unverändert.

Panniculus hellgelb, Pectoralis dunkelrot, transparent. Zwarchfellstand rechts 3., links 4. Rippe. Loberrand in der rechten Mammillarlinie etwas oberhalb des Rippenbogens, in der Mittellinie $8 \mathrm{~cm}$ unter dem Ende des Corpus sterni. Omentum majus lang, ziemlich fettreich, ebenso im Masenterium sehr viel Fettgewebe. Därme etwas gebläht. Serosa glatt und glänzend. Processus vermiformis frei, Harnblase wenig gefüllt. Im Abdomen keine Flüssigkeit.

Lungen retrahiert, frei. Pleurahöhlen leer. Im vorderen Mediastinum ziemlich viel Fettgewebs. Im Herzbeutel ca. $20 \mathrm{ccm}$ klare, gəlbə Flüssigkeit. Herz nach 
beiden Seiten verbreitert, sehr schlaff, sehr viel subepikardiales Fettgewebe. In den Herzhöhlen flüssiges Blut und etwas Cruor. Atrioventrikularklappen fast für drei Finger durchgängig. Arterielle Ostien suffizient. Im langen Mitralsegel einige gelbe, trübe Plaques. Aortenklappen am Ansatz verdickt. Klappen des rechten Herzens o. B. Sämtliche Klappen leicht ikterisch verfärbt. Wanddicke links 10, rechts $3 \mathrm{~mm}$. Myokard braunrot, leicht getrübt, Spitze der Ventrikel stark von Fett durchwachsen. Beide Ventrikel dilatiert. In den Coronararterien einige trübe, gelbe Plaques. Foramen ovale geschlossen.

Zunge bräunlich belegt, Balgdrüsen und Tonsillen o. B. Im unteren Teil des Oesophagus starke Cyanose und Füllung der Venen. In Larynx und Trachea schaumig-seröse Flïssigkeit, leichte Injektion der Schleimhaut. Glandula submaxillaris beiderseits mit dunkelbraun pigmentierten Drüsenläppchen. Schilddrüse normal groß, ohne Knoten. Drüsenläppchen klein, dunkelbraun gefärbt. In der Aorta ascendens über den Klappen einige trübe, gelbe Plaques, ebenso in der Aorta descendens thoracica. In der Aorta abdominalis zahlreiche Plaques und einige längliche Geschwüre mit unregelmäßigem Grund. Lungen normal groß. Unter der Pleura einige rundliche Blutungen von $1-5 \mathrm{~mm}$ Durchmesser. Pleura glatt und glänzend. Luftgehalt der Lungen gut. Schnittflë,che glatt, dunkelrot. Gewebe stark bluthaltig und ödematös. Im linken Unterlappen eine herdförmige Blutung von ca. $2 \mathrm{~cm}$ Durchmesser, kleinere Blutungen rechts. Nirgends Tuberkel oder Narben. Lungenarterien o. B. In den Bronchien viel schaumig-seröse Flüssigkeit. Schleimhaut injiziert. Bronchialdrüsen klein, anthrakotisch.

Milz mit Zwerchfell, Magen und Schwanz des Pankreas verwachsen, ungefähr auf das Doppelte vergrößert. Konsistenz normal. Kapsel verdickt. Pulpa dunkelrot, sehr blutreich. Follikel nicht deutlich, Trabekel verdickt. Nebennieren normal groß, Rinde außen gelb, innen braun. Mark mäßig reichlich, zum Teil erweicht. Nieren normal grob. Kapsel gut abziehbar, fettreich. Oberfläche glatt. Schnittfläche leicht getrübt, Zeichnung deutlich. Rinde etwas bräunlich. Mark graurot. Konsistenz etwas vermindert, Brüchigkeit normal. Nierenbecken o. B. Magen mäßig weit, Schleimhaut injiziert und namentlich im Fundus leicht pigmentiert. Duodenum o. B. Choledochus durchgängig.

Leber stark vergrößert, Oberfläche fein granuliert, dunkelbraun, Granula von ca. $1 \mathrm{~mm}$ Durchmesser. Konsistenz stark vermehrt. Lebergewebe schwer zu schneiden. Auf der Schnittfläche eine gleichmäßige, feine Granulierung, die Granula dunkelbraun, zum Teil leicht getrübt, von 1-2 mm Durchmesser, dazwischen graurotes Bindegewebe, welches stellenweise breitere Septen von 2-5 mm Durchmesser bildet. Gewebe nicht brüchig, sehr zäh. Pfortader und ihre Äste etwas erweitert und leicht verdickt, jedoch ohne Plaques. Gallenblase sehr stark gefüllt mit dunkelgrüner, dünnflüssiger Galle und einigen kleinen, schwärzlichen, weichen Konkrementen. Schleimhaut o. B.

Pankreas leicht vergrößert, sehr derb, Drüsenläppchen braun, zwischen ihnen breite Septen von Bindegewebe.

Retroperitoneal- und Periportaldrüsen stark vexgrößert, weich, Schnittfläche dunkelbraun, Mesenterialdrüsen klein, Schnittfläche graurot. In der Harnblase wenig klarer, gelber Urin. Schleimhaut leicht injiziert. Prostata und Samenblasen o. B. Keine vermehrte Pigmentierung. Hoden und Nebenhoden normal groß, Hoden gelbbrätunlich, Nebenhodenkopf bräunlich.

Im Darm sehr viel dünnbreiiger, gelbbräunlicher Inhalt. Schleimhaut injiziert, hier und da kleine Blutungen. Distales Ende des Processus vermiformis obliteriert.

Bei der ganzen Sektion fällt der eigentümliche Geruch der Organe nach Fruchtsäure auf.

Die mikroskopische Untersuchung der Organe ergibt folgendes: 


\section{H. Schuppisser: Über Eiseninkrustation der Bindegewebssubstanzen}

Leber: Die Leber bietet das Bild der annulären Cirrhose, indem zwischen breiten, konfluierenden Bindegewebssepten größere und kleinere, meist rundliche Inseln von Leberzellgewebe ohne Vena centralis liegen. Die Größe der Läppchen schwankt zwischen 1-2 mm. Die Zellen sind stark postmortal verändert, die Kerne nicht mehr färbbar. Die Leberzellen enthalten meist reichlich feine oder gröbere Körner von dunkelgelber bis bräunlicher Farbe, in der Ablagerung läßt sich eine Bevorzugung von Peripherie oder Zentrum der Inseln nicht erkennen. Wenige Leberzellen sind fetthaltig, mit großen Fetttropfen angefüllt. Auch die Sternzellen enthalten bräunliches Pigment. Die Septen bestehen aus grobfaserigem Bindegewebe, hier und da sind neugebildete Gallengänge zu sehen. In den Interstitien mäßige lymphocytäre Infiltration und, regellos angeordnet, sehr reichliche, grobe Körner und Schollen eines dunkelbraunen Pigments, meist intracellulär in Bindegewebszellen gelegen. Auch das Epithel der Gallengänge enthält stellenweise dieses Pigment. Fast alles Pigment ergibt mit der Berlinerblau- und der Turnbullreaktion intensive Blaufärbung. Nur ganz vereinzelt in den Epithelien braune Körner, die keine Fe-Reaktion geben.

Pankreas: Das interlobuläre Bindegewebe ist beträchtlich vermehrt. Die Struktur der Acini ist stark verändert, so daß meist die einzelnen Drüsenschläuche nicht mehr zu erkennen sind. Die Epithelien sind sehr schlecht konserviert und liegen locker durcheinander, die Kerne sind meist nicht mehr färbbar. Langerhanssche Inseln sind nicht zu erkennen. In den Epithelien reichlich feinkörniges, in den Septen grobkörniges und scholliges, dunkelbraunes Pigment, das wohl größitenteils intracellulär liegt. Fast sämtliches Pigment gibt intensive Eisenreaktion, nur ganz selten im Epithel bräunliche oder gelbliche Körner, die keine Fe-Realktion geben. Die glatte Muskulatur der Arterien ist frei von Pigment. In der Wand eines großen Ausführungsganges mehrere, unregelmäßig eckige Kalkschollen. Manche Läppchen sind stark atrophisch, zwischen ihnen findet sich reichliches Fettgewebe.

Milz: Kapsel 0,5 mm dick, aus hyalinem Bindegewebe bestehend, in den spärlichen, spindelförmigen Bindegewebszellen viel braunes Pigment. Trabekel stark verdickt, Follikel normal groß, die Follikelarterien zeigen häufig hyaline Verdickung der Wandung. Bindegewebe der Pulpa nicht vermehrt, in letzterer liegen mäBig reichlich oder spärlich feine und gröbere Körner von Hämosiderin, sowohl innerhalb wie außerhalb der Pulpazellen. In den Trabekeln kein Pigment, hier und da Hämosiderinschollen um die Follikelarterien.

Niere: Interstitielles Bindegewebe ganz leicht und diffus vermehrt, im übrigen ist die Struktur vollkommen erhalten. Die Epithelien der Harnkanälchen haben nur noch selten färbbare Kerne. In einigen Schaltstücken, selten in den Hauptstücken und dünnen Schleifenschenkeln enthalten einzelne Epithelien reichlich Hämosiderinkörner, in den Gefäßendothelien der Glomerulusschlingen lassen sich besonders mit der Turnbullfärbung mäßig zahlreiche, meist feine, hier und da auch größere Körner von Hämosiderin nachweisen. Das Epithel der dünnen Schleifenschenkel und der Schaltstücke enthält mäßig reichlich feine Fetttröpfchen.

Hoden: Epithelien der Samenkanälchen desquamiert, keine Spermatozoen, die Membranae propriae und das Zwischengewebe sind leicht verdickt. Zwischenzellen nicht vermehrt. Hier und da leichte Verfettung der Epithelien, auch der Zwischenzellen. Pigment findet sich spärlich in den Bindegewebszellen, etwas reichlicher in den Endothelien der kleineren Gefäße, überall in Form von feinkörnigem, hellbraunem Hämosiderin.

Lungen: In den Alveolarsepten stark gefüllte und ins Lumen vorspringende Gefäße; in den Alveolen reichliche Ödemflüssigkeit, rote Blutkörperchen und desquamierte Alveolarepithelien, stellenweise auch ziemlich reichlich polymorphkernige, neutrophile Leukocyten. Zahlreiche Alveolarepithelien sind mit anthra- 
kotischem Pigment gefüllt, nur spärliche besitzen neben den schwarzen noch braune, die Eisenreaktionen gebende Körner. Hier und da im periarteriellen Bindegewebe intracelluläres Hämosiderin.

Herz: Fasern fragmentiert, Kerne nicht mehr färbbar. In den Fasern finden sich fleckweise sehr zahlreiche, meist in Längsreihen, hier und da auch in Querreihen angeordnete, feine, braungelbe Körner, die meist intensive Eisenreaktion geben, jedoch finden sich neben den bexlinerblauen Körnern Häufchen von gelben Körnern, die die Fe-Reaktion nicht geben und wohl als Lipofuscin anzusprechen sind.

Quergestreifte Skelettmuskulatur: Mit starker Vergrößerung sind im Sarkoplasma um die Pole der Sarkolemmkerne angeordnete, sehr kleine, brane Körner sichtbar; mit den Eisenreaktionen lassen sich diese feinen Körner, zu kurzen Längsstreifen angeordnet, unter dem Sarkolemm in größerer Zahl nachweisen.

Magen: Die Schleimhaut ist sehr schlecht erhalten, die oberflächlichen Teile fehlen stellenweise. Kernfärbung ist fast in der ganzen Schleimhaut nicht mehr zu erzielen. In den Drüsenschläuchen ist das Epithel desquamiert und enthält, namentlich im Grunde der Drüsenschläuche, sehr reichlich eisenhaltiges, ziemlich grobkörmiges Pigment. In der Tunica propria und in der Muscularis mucosae kein Pigment. In der Submucosa enthalten einige Bindegewebszellen eisenhaltiges Pigment. Die glatten Muskelzellen der Gefäßwände enthalten hellgelbe, feine Körner, die keine Eisenreaktion geben.

Glandula submaxillaris: Die Drüsenzellen der Endstücke enthalten reichlich feine Hämosiderinkörner, namentlich die serösen Zellen, deren Pigment gegen das Lumen zu gelegen ist. Die mukösen Drüsenzellen enthalten etwa\$s spärlicheres und mehr basal gelagertes Hämosiderin. Auch die Schaltstücke sind sehr stark befallen, die Sekretröhren nur wenig. Zudem findet sich in zablreichen serösen Zellen sowie in den glatten Muskelzellen der Arterien gelbliches, die Eisenreaktion nicht gebendes Pigment.

Schilddrüse: Das inter- und intralobuläre Bindegewebe ist vermehrt, die Follikel sind klein bis mittelgroß, enthalten dickffüssiges, peripher eosinophiles, zentral basophiles Kolloid. Die Epithelien sind abgeplattet oder kubisch, enthalten sehr reichlich grob- und feinkörniges Hämosiderin, ferner oft kleinere und größere Fetttröpfehen. Nicht selten finden sich in den Zellen auch feine Körnchen, die sich deutlich mit Scharlachrot färben. In den Septen k]eine Haufen stark mit Hämosiderin beladener und mit Fetttröpfchen angefüllter, polyedrischer Zellen, wobl untergehende Follikel. Die Bindegewebszellen enthalten nur selten Pigment.

Haut: Im Stratum Malpighi der Epidermis, besonders der Basalzellenschicht, sehr feines, körniges Pigment, das die Eisenreaktion nicht gibt. Im Stratum papillare reichliche Infiltration mit Lymphocyten, ebenso um die Gefäße und Schweißdrüsenknäuel herum. Überall im Corium, besonders im Stratum papillare und um die Membrana propria der Schweißdrüsen finden sich kleine, mit feinkörnigem Hämosiderin beladene Spindelzellen.

Dies der histologische Befund der Organe. Es handelt sich also um einen typischen Fall von Hämochromatose mit ganz ausgedehnter Ablagerung von Pigment, das meist dem Hämosiderin entspricht, zum kleineren Teil aber keine Eisenrealtion gibt und wohl das von den früheren Autoren als Hämofuscin bezeichnete Pigment ist. Auf eine nähere Besprechuing der Hämochromatose können wir uns hier nicht einlassen, da uns bei dieser Arbeit nur die Veränderungen in den retroperitonealen Lymphdrüsen näher interessieren. 
Hier ergibt sich bei der mikroskopischen Untersuchung folgendes:

Lymphadenoides Gewebe ist nur noch an einigen Stellen reichlicher und in der für Lymphdrüsen typischen Anordnung vorhanden, in Form rundlicher, den Lymphfollikeln an Größe entsprechender Lymphocytenanhäufungen, die oft unter sich verschmelzen, oder als schmale Zellstränge, die hier und da an Markstränge erinnern. Die Kerne der Lymphocyten sind bei der Hämalaunfärbung nur zum kleinen Teil schön blau gefärbt, sie zeigen alle Ủbergänge bis zur vollständigen Abblassung, was auf postmortale Einwirkung zu beziehen ist. In den besser erhaltenen Partien sind zwischen dem lymphatischen Gewebe noch deutliche Lymphsinus zu erkennen.

Im übrigen ist das normale Bild der Lymphdrüsen starţ verändert und zwar einmal durch eine starke Bindegewebszunahme. Die Bindegewebskapseln der Lymphdrüsen sind ziemlich stark verdickt, von ihnen gehen zahlreiche, mäßig breite und of $t$ verzweigte Trabekel in die Tiefe, das lymphatische Gewebe in kleinere Bezirke abteilend, hier und da umschließen sie auch nur einzelne Lymphfollikel. Sie bestehen meist aus hyalinem, kernlosem Gewebe. Des weiteren findet sich in den stärker veränderten Teilen der Lymphdrüsen auch zwischen den Trabekeln an Stelle des teilweise oder vollständig zuxücktretenden lymphatischen Gewebes ein spärliches, mehr auf das Zentrum der Follikel beschränktes oder ein ausgedehnteres, unregelmäBiges Geflecht von breiten beinahe kernlosen Bindegewebsbalken eingelagert, die sich mit Eosin hellrot, nach van Gieson dunkelrot färben und somit dem conjunetivalen Hyalin entsprechen.

Vor allem aber wird das Bild beherrscht durch eine mehr oder weniger massenhafte Ablagerung eines dunkelbraunen Pigmentes. Dieses gibt sich insgesamt als Hämosiderin zu erkennen: Es ist vollkommen löslich in verdünnten Säuren, unlöslich in Kalilauge, bleicht sich nicht in Wasserstoffsuperoxyd und gibt sämtliche Eisenreaktionen. Das Pigment liegt einmal in den besser erhaltenen Abschnitten der Lymphdrüsen vorerst nur in den Endothelien der Sinus eingelagert, und zwar als feine, rundliche oder eckige Körner von bräunlicher bis dunkelbrauner Farbe. Durch die reichliche Ablagerung desselben sind die Kerne der Zellen meist vollständig verdeckt, hingegen kommt die rundliche, spindelförmige oder verzweigte Gestalt der Zellen sehr scharf zum Ausdruck. Die Follikel sind nur zum kleinen Teil von der Farbstoffablagerung verschont, meist findet sich an der Peripherie im Anschluß an die mit Pigment beladenen. Sinusendotheizellen ein schmälerer oder breiterer Saum stark bräunlich gefärbt, indem hier zwischen den Lymphocyten sehr reichlich feine Kömer und kleinere und gröbere Schollen dieses bräunlichen bis schwärzlichen Pigments abgelagert sind. Hier und da liegen die Körner noch in scharf begrenzten rundlichen Haufen zusammen, was auf eine intracellulare Ablagerung in Reticulumzellen schließen läßt, zum größeren Teil aber liegen die Körner und Schollen ganz regellos durcheinander. Neben diesen nur spärlich und peripher mit Pigment beladenen Follikeln liegen solche, in denen nur noch eine kleine, zentrale Partie frei ist, während sonst überall die Lymphocyten bis auf spärliche Elemente yerdrängt sind; sodann zahlreiche Follikel, in welchen das lymphatische Gewebe vollkommen, auch im Zentrum, durch die Körner und Schollen ersetzt ist, welche rundliche, oft unter sich zusammenhängende, aus Pigment bestehende Haufen bilden.

Auch an den Stellen mit hyaliner Entartung sieht man an den rom Bindegewebe freigelassenen Lücken eine äußerst reichliche Ablagerung des Pigments, und zwar vorwiegend in Form von kleineren und größeren Schollen, wodurch das lymphatische Gewebe noch stärker zwrïckgedrängt erscheint nud nur noch in unregelmäBigen, Kleinen Haufen von Lymphocyten anzutreffen ist. Durch die durchziehenden Trabekel werden diese am stärksten veränderten Teile in verschie- 
den große, rundliche oder längliche Bezirke abgeteilt, in welchen bèi der Hämalauneosinfärbung neben den tiefbraunen, pigmentierten Stellen durch das reichliche, eingelagerte Bindegewebe verschieden große, hell- bis blaßrote Partien zu sehen sind.

In dieses Bindegewebe eingelagert oder auch frei zwischen den Pigmentschollen liegend, oder nur in eine blasse, hyaline Substanz eingebettet, findet sich nun ein feines Gitterwerk aus ziemlich dünnen, mäßig langen, geraden Stäbchen eingelagert, die derart zusammenhängen, daß in ziemlich regelmäßiger Weise je 3-4 Bälkchen unter spitzem oder stumpfem Winkel in einem Knotenpunkt zusammentreffen. Dadurch kommt ein äußerst zierliches, auch in die dritte Dimension sich ausdehnendes,

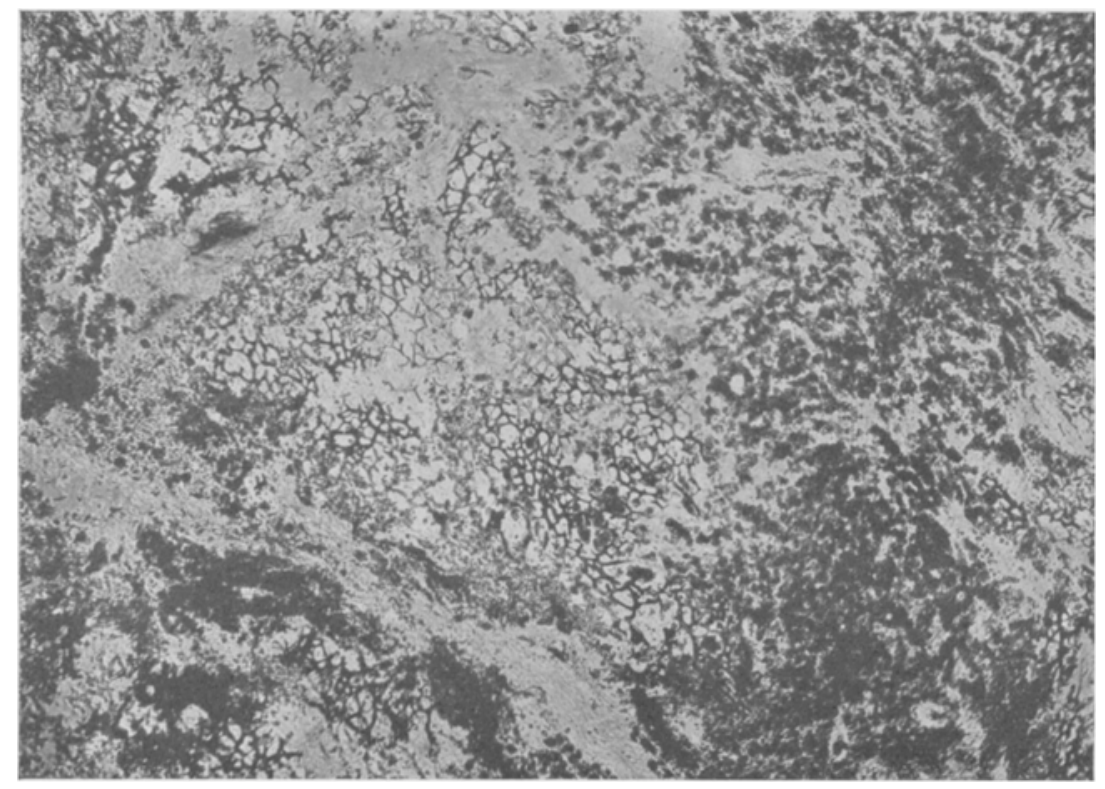

Abb. 1. Mit Eisen und Kalk inkrustierte Gitterfasern in einer retroperitonealen Lymphdrüse. (Fall 1.) Vergrößerung $80 \mathrm{fach}$. Färbung mit Hämalauneosin. In der Mitte doppeItkonturierte helle Balken, die nur aus Eisen bestehen. In der Peripherie sehr reichlich Hämosiderin.

spongiöses Gerüstwerk zustande, zwischen welchem regelmäßige Maschen- oder Hohlrärume liegen. Die Bildungen erinnern oft an Skelette von Radiolarien. Die Balken besitzen eine Länge von $12-14 \mu$ und eine Dicke von 2,5-4 $\mu$. Sie umschließen polyedrische Maschen von 10-25 $\mu$ Durchmesser (Abb. 1).

Im ungefärbten Präparat erscheinen die Balken scharf konturiert, glänzend, meistens vollkommen farblos und durchsichtig, selten ganz leicht gelblich. Doppeltbrechend sind sie nicht.

MitHämalaunfärben sie sich zum großen Teil intensiv blau. Da, wo das Maschenwerk frei zwischen den Pigmentschollen liegt, erscheinen freilich unregelmäßige Partien desselben nur schwach blau und werden dabei durchsichtiger, vielfach entbehren sie jeglichen blauen Farbentones und sind dann hellgelb bis hellgrün und besitzen beinahe eine glasartige Durchsichtigkeit. Die blauen Balken gehen ohne scharfe Grenze in die hellen über. Die Knotenpunkte der blauen Stäbchen imponieren oft als rundliche, tiefblaue oder schwarze Punkte, die dadurch zustande 


\section{H. Schuppisser: Über Eiseninkrustation der Bindegewebssubstanzen}

lrommen, daß hier ein kürzerer oder längerer Abschnitt eines Bälkchens in der axialen Richtung gesehen wird und dabei stärker tingiert erscheint. Hier und da finden sich quere Bruchlinien durch die Balken, was wohl als Kunstprodukt aufzufassen ist. Diese Maschenwerke liegen also im Innern der bindegewebig entarteten und mit Pigment überladenen Follikel und haben oft eine rundliche oder mehr ovale Begrenzung und eine im ganzen sehr verschieden starke Ausdehnung. Sie dehnen sich stellenweise über mehrere der nicht mehr scharf voneinander zu trennenden Lymphfollikel aus, an anderen Stellen finden sich dagegen nur ganz vereinzelte blaue oder helle Balken, die aber immer in der oben beschriebenen Weise zu einem Gitterwerk zusammengefügt sind. Oft erscheinen einzelne ringförmige, einen Kreis umschließende Balken von einer Dicke von 2,5-3 $\mu$, die ohne weiteres als Gefäßwände imponieren. Das von ihnen umschlossene Lumen hat einen Durchmesser von 25-32 u. Ferner sieht man auch Längsschn tte durch derartige Gefäße in Form von zwei geraden, vollkommen parallel verlaufenden Balken, die eine Länge bis zu $50 \mu$ besitzen können. Von diesen Gefäßen strahlen oft Gerüstwerke der oben beschriebenen Bälkchen radiär in das umgebende Gewebe aus. Neben diesen gleichmäßigen Strukturen finden sich auch unregelmäßig gebaute Netzwerke, indem hier Bälkchen von verschiedener Länge und Dicke und etwas gekrümmtem Verlaufe zu einem Verbande geordnet sind. Entsprechend sind dann auch hier die Maschenräume zu ganz verschiedenen Formen verzogen. Auch diese Netzwerke hängen öfters mit in gleichem Sinne veränderten Gefäßwänden zusammen. In den Lymphfollikeln, die nicht bindegewebig verödet und mit Pigment überhäuft sind, sind diese Bildungen nicht anzutreffen.

Bei der näheren Untersuchung mit chemischen und färberischen Methoden lassen die Balken folgendes erkennen: Mit verdünnter Salqsäure entwickeln sich an ihnen mäßig reichliche Gasblasen, mit verdünnter Schwefelsäure reichlich Gipsnadeln.

Die Kalkfärbungen ergeben folgendes Resultat: Bei der von Roehl angegebenen Methode (Färbung in 1 proz. wässeriger Hämatoxylinlösung nach Behaindlung mit Oxalsäure, Differenzieren in mit Ammoniak versetztem Aq. dest.) färben sich die Bälkchen meist blau-blauviolett, zum kleineren Teil haben sie das Hämatoxylin nur spurweise angenommen oder sind vollkommen ungefärbt, von glasartigem, hellem Sussehen. Bei dem Verfahren nach Kossa (Reduktion von Silbernitrat bei Einwirkung von Tageslicht) werden die Balken meist tiefschwarz, an zahlreichen Stellen aber auch nur dunkelbraun bis hellgoldbraun gefärbt, und zwar gehen diese Färbungen kontinuierlich ineinander über. Mit Rücksicht darauf, daß der gesamte Schnitt sich bei dieser Reaktion gelbbraun gefärbt hat, sind die hellbraunen Partien des Gerüstwerkes als Stellen mit fehlendem Kalkgehalt zu betrachten, auch ist an den übrigen Balken der Grad der Verkalkung ein verschieden weit fortgeschrittener, worauf wir auch aus dem Ausfall der Roehlschen Färbung schließen können. Ob die kalklosen Partien des Balkenwerkes genau den bei der Hämalauneosinfärbung ungefärbt und hellgrün erscheinenden entsprechen, konnten wir leider nicht genau feststellen. Doch erscheint uns dies in hohem Grade wahrscheinlich, denn in beiden Präparaten ist das Mengenverhältnis der ungefärbten zu den gefärbten Balken ungefähr das nämliche. Auch sind in den zusammenhängenden Gerüstwerken in beiden Schnitten vorzüglich die peripheren Teile ungefärbt.

Sehr naheliegend war auch die Probe auf den Eisengehalt der Ballken. Die Eisenreaktionen geben nun prächtige Bilder, die das feine Gitterwerk der Kalkstäbchen noch viel schöner hervortreten lassen als die Hämalaun- oder Silberfärbung. Zunächst färben sich die Stäbchen mit Schwefelammon schmutzig grün bis dunkelgrün, zum großen Teił aber vollkommen schwarz. Bei der nachfolgenden Behandlung mit Ferricyankali und Salzsäure (Turnbullreaktion) färben sich sämt- 
liche Balken teils hellblau, meist aber erscheinen sie in einem leuchtenden, intensiven Kornblumenblau. Bei der Berlinerblaureaktion mit Ferrocyankali und Salzsäure färbt sich ein großer Teil der Balkenwerke tiefblau oder hellblau, während zahlreiche Flechtwerke, meist solche, welche im Bindegewebe eingeschlossen sind, ungefärbt bleiben. Gefärbte und ungefärbte Balken gehen an einigen Gerüstwerken ohne scharfe Grenze ineinander über. Die Eisenreaktion fällt also stark positiv aus, wobei bei der Turnbullreaktion das Eisen vollständiger zux Darstellung gelangt als bei der Berlinerblaureaktion.

Um über das Verhältnis der Balkenwerke zum Reticulum besser ins Klare zu kommen, habe ich die Versilberung nach Bielschowsky.Maresch vorgenommen. Bei dieser läßt sich an zahİreichen. Stellen ein Maschenwerk aus feinen, hellbraun- bis schwarzgefärbten Fibrillen darstellen, die oft auch strahlig von Gefäßquerschnitten abgehen, sich aber von den verkalkten Stäbchen durch ihren oft etwas gewundenen: Verlauf und viel geringere Dicke unterscheiden. Die verkalkten Gitter selbst sind meist tiefschwarz, hier und dai auch dunkelbraun gefärbt. Am Rande der verkalkten Netze gehen die verkalkten Balken stellenweise deutlich in die Fibrillen über. Dieses Verhalten bringt den Beweis, dạ es bei diesen Formen sich um Veränderungen der reticulären Stützsubstanz des lymphatischen Gewebes handelt.

Bei der Färbung nach van Gieson färbt sich das Gitterwerk hellblau bis dunkelblau, jedoch sind auch zahlreiche Partien der Gitter nur ganz blaßblau tingiert und erscheinen durchsichtig. Ferner sind wie bei der Hämalaunfärbung noch vollkommen ungefärbte, schwachgrünlich aussehende Bälkchen anzutreffen. Ina Gegensatz dazu ist das Bindegewebe hellrot bis dunkelrot gefärbt. Die tiefrot gefärbten, aus conjunctivalem Hyalin bestehenden Massen treten meistens gemeinsam mit dem verkalkten Stützgewebe auf. Und zwar lagern sie sich deutlich den verkalkten Stäbchen allseitig als breite Balken an, von ihnen durch eine feine, helle Spalte deutlich abgesetzt, in ihrem Verlauf genau den Balken folgend. An anderen Stellen ist die Ablagerung des Hyalins auf die verkalkten Balken noch weiter fortgeschritten, indem das ganze Maschenwerk zwischen denselben lückenlos durch eine hellrot oder dunkelrot gefärbte, vollkommen homogene Masse ausgefüllt ist. Neben den mit Hyalin umscheideten Balken finden sich aber auch Netzwerke von verkalkten Balken, die einer solchen Umhüllung vollkommen entbehren und frei zwischen den Pigmentschollen und Lymphocyten liegen.

Wenn ich meine Befunde zusammenfasse, findet sich also bei diesem Falle von allg. Hämochromatose in den retroperitonealen Lymphdrüsen eine ganz eigenartige Form von Eisen- und Kallinkrustation, und zwar belrifft dieselbe selektiv das retikuläre Stuitzgewebe in einer Weise, wie sie meines Wissens noch nie beschrieben worden ist. Diese führt zur Bildung eines: äußerst zierlichen, durch einen meist sehr regelmäBigen Aufbau ausgezeichneten Gitterwerkes, das sich aus feinen Bälkchen zụsammensetzt. Daß der Kalk und das Eisen hier in die Gitterfasern selbst abgelagert sind, beweist die Bielschowskyfärbung, bei welcher der Nachweis erbracht ist, daß die Gitterfasern direkt in die Balkenwerke übergehen. Der Eisengehalt der Bälkchen ist überall ein sehr intensiver und konstanter (Turnbullreaktion). Demgegenüber ist der Grad der. Verkalkung des Gitterwerkes ein sehr wechselnder, indem sowohI die Kossasche Silberreaktion als die Roehlsche Kalkfärbung in kontinuierlichem Ubergange bald stank positiv, bald nur 
sehr schwach positiv oder vollkommen negativ ausfallen. Damit kann das im Hämalaun- und van Gieson-Präparat zur Darstellung gelangende, ungleiche färberische Verhalten des Balkenwerkes dem Hämatoxylin gegenüber sehr gut in Beziehung gebracht werden, indem nicht sämtliche Bälkchen blau gefärbt sind, sondern eine große Zahl derselben das Hämatoxylin nur sehr schwach oder gar nicht angenommen hat und statt dessen das oben beschriebene, eigentümliche hellgrüne oder hellgelbe, transparente Aussehen besitzt. Wir sind der Ansicht, daß die im Hämalaunpräparat hellen Partien des Balkenwerkes als Stellen mit fehlendem Kalkgehalt aufzufassen sind, und daß das transparente Aussehen der Balken auf den alleinigen Gehalt an Eisen zurückzufübren ist. Dafür sprechen die bereits oben angeführten Gründe, ferner der Umstand, daß bekanntermaßen Konkremente aus Kalk bei Hämalaunfärbung das Hämatoxylin wenigstens in den Randzonen leicht annehmen, während unsere hellen Balken sich gegenüber dem Hämatoxylin vollkommen refraktär verhalten. Dieser auffällige Befund, daß der Eisengehalt genannter Gitterwerke sehr konstant, der Kalkgehalt aber an zahlreichen Stellen sicher negativ ist, läßt uns den Schlu $B$ als gerechtfertigt erscheinen, in dieser gleichzeitigen. Ablagerung von Kalk und Eisen in den Gitterfasern nicht ein zufälliges Nebeneinander dieser Stoffe zu erblicken, sondern wir neigen dazu, die Eisenablagerung im Reticulum als das Primäre, das Ausschlaggebende zu betrachten und die Verkalkung als das sekundär Hinzugekommene. Durch die zuerst erfolgende Eisenaufnahme wird das Reticulum in das starre Gerüstwerk umgewandelt, wobei die Reticulumfasern an Dicke um das Mehrfache zunehmen, ihren gewundenen Verlauf einbüßen und zugleich ein helles, glasartiges Aussehen erhalten, d. h. also sich in das helle Balkenwerk umwandeln. Die Inkrustation mit Eisen bedingt nach unserer Auffassung zudem eine chemische Umwandlung der Fibrillensubstanz, die sich in einer starken Affinität zu Kalksalzen ausdrückt, was dann zur Adsorption von Calcium aus der Gewebsflüssigkeit und zum Niederschlag desselben in die Balken führt. Das Eisen würde also bei dieser pathologischen Verkalkung die gleiche Rolle spielen, wie sie ihm von Schmorl bei der normalen Verknöcherung zugedacht worden ist, $d . h$. es diente gleichsam als Beize für die nachherige Kalkablagerung. Für die primäre Rolle des Eisens beim Zustandekommen dieser Verkalkung spricht uns auch der Umstand, daß sich das Balkenwerk nur an Stellen ausgebildet hat, wo im umliegenden Gewebe sehr viel Eisen in Form von intra- und extracellulärem Hämosiderin vorhanden ist, in den eisenpigmentfreien Stellen aber vollkommen fehlt. Zudem ist diese Art von Verkalkung in Lymphdrüsen eine so einzigartige und seltene, der Eisenpigmentgehalt der Lymphdrüsen auf der anderen Seite ein so außerordentlich großer, 
daß es von vornherein wahrscheinlich erscheint, daß dem Eisen hier bei der Entstehung dieser Verkalkung eine besondere Bedeutung zukommt.

Bei den bisher bekannten Verkalkungen in Lymphdrüsen findet die Kalkablagerung stets in nekrotischen Massen, z. B. im. tuberkulösen Käse oder in einem hyalin umgewandelten Reticulum statt, das seine normale Struktur vollkommen eingebüßt hat. Es handelt sich also hier um die gewöhnliche Form der dystrophischen Verkalkung, wäbrend in meinem Falle die Dystrophie nur in der Eiseninkrustation des Retikulums, ohne gleichzeitige stärkere Strukturveränderungen desselben besteht: Wir haben also hier eine ganz spezielle Form von dystrophischer Verkalkung vor uns.

Wir haben natürlich bei diesem Befunde von gleichzeitiger Ablagerung von Eisen und Kalk auch an die Möglichkeit einer postmortalen Imbibition des Kalkes mit Eisen gedacht, besonders da Hueck sehr ausdrücklich vor der Gefahr einer postmortalen Imbibition verkalkter Gewebe mit Eisen gewarnt hat, wie sie sehr leicht durch eisenhaltige Flüssigkeiten oder durch langes Stehen in Formalin oder Alkohol zustande kommt. Unsere Schnitte weisen nun nicht mehr in in allen Teilen die wünschenswerte deutliche Färbbarkeit auf (schlechto Kernfärbbarkeit der Lymphocyten). Die Sektion wurde 19 Stunden nach dem Tode ausgeführt, die Organe kurz, höchstens 24 Stunden, in Formol fixiert, wobei allerdings die Konservierungsflüssigkeiten nicht auf ihren Eisengehalt geprüft wurden. Die Berlinerblau- und Turnbullpräparate lassen auch stellenweise eine leichte diffuse Durchtränkung des Gewebes mit gelöstem, reagierendem Eisen erkennen. Wir müssen, besonders da die Sektion relativ spät ausgeführt wurde, die Möglichkeit einer nachträglichen Eisenimbibition zugeben. Wenn wir trotz dieser Faktoren eine postmortale Imbibition des verkalkten Reticulums mit Eisen ausschließen zu können glauben, so stützen wir uns dabei vor allem auf die Tatsache, daß die Balkenwerke an vielen Stellen nur Eisen und keinen Kalk enthalten, was niemals mit der Ansicht von einer bloßen postmortalen Imbibition des Kalkes mit Eisen in Einklang zu bringen ist, auch nicht mit einer intravitalen, aber passiv erfolgten, durch bloße Affinität des Kalkes zu Eisen herbeigeführten Beladung des Kalkes mit Eisen. Ein nachträglicher Entzug von Kalk aus den Balken, was auch zu einem stellenweisen Fehlen von Kalk führen könnte, ist sicher auszuschließen, da die Organe vor ihrer Untersuchung nur kurze Zeit in Formol gelegen haben.

Der enorme Eisengehalt der Lymphdrüsen steht mit der Grundkrankheit, der Hämochromatose, in Beziehung. Nach Ansicht der meisten früheren Autoren ist die Krankheit bedingt durch einen äußerst chronischen Blatzerfall, hervorgerufen durch Resorption von schäd- 


\section{H. Schuppisser: Über Eiseninkrustation der Bindegewebssubstanzen}

lichen Stoffwechselprodukten vom Darme aus, für welche die meist zugleich bestehenden chronischen Verdanungsstörungen den Grund abgeben (Ungeheuer, Straeter). Rößle nimmt an, daß das Wesen der Hämachromatose auf einer infektiös-toxischen Erkrankung der Capillaren beruhe, die zu einem Untergang der Capillarwände mit hämorrhagischem Ödem führt und im Anschluß hieran zur Aufnahme roter Blutkörper durch die Parenchymzellen, wobei dann die phagocytierten Blutkörper von den Epithelien in Pigment umgewandelt werden. In dieser Phagocytose sieht er den für das Zustandekommen der Hämochromatose wesentlichen Vorgang, während er die bei anderen krankhaften Zuständen vorkommenden Pigmentierungen der Epithelien mit eisenhaltigem Blutfarbstoff als eine Folge intravasculären Blutzerfalles betrachtet, wobei das Pigment den Epithelien in fertigem Zustande zugeführt werden soll. Würde diese Entstehungsart für die Hämachromatose zutreffen, wofür sich allerdings in unserem Falle weder in Leber noch in Pankreas sichere Anhaltspunkte bieten, so könnte man für den enormen Pigmentreichtum der retroperitonealen Lymphdrüsen eine übermäßig starke Zufuhr von roten Blutkörpern oder bei deren Zerfall an eine Zufuhr von gelöstem Blutfarbstoff auf dem Lymphwege verantwortlich machen. Jedenfalls würde dieser Vorgang, der auch schubweise vor sich gehen könnte, in unserem Falle schon weit zurückliegen. Nach Anschütz wird den Zellen mit den Gewebssäften gelöster Blutfarbstoff, berrührend von kleinen, aber konstanten intravasculären Blutzersetzungen, zugeführt. Zugleich aber hält er für das Zustandekommen der Hämochromatose eine schwere Zellalteration unbekannten Ursprungs für notwendig, welche sich in einem abnormen Speicherungs- und Festhaltungsvermögen von Eisen äußert. Mit dieser Ansicht ist er also schon sehr früh der heutigen von Lubarsch aufgestelliten Theorie nahe gekommen. Dieser hat namentlich auf den auffallenden Gegensatz hingewiesen, der sich bei der Hämochromatose zwischen den in ganz ungewöhnlich ausgedehntem Maße vorhandenen Hämosiderinablagerungen und dem dabei nur in ganz geringem Grade bestehenden Zustand von Anämie vorfindet. Nach ihm liegt die Ursache der Hämochromatose nicht in erster Linie in dem (oft überhaupt nicht nachweisbaren) Blutzerfall, sondern in einer Störung des Eisenstoffwechsels der Zellen. Es besteht ,eine toxische Zellschädigung, die dazu führt, daß das Eisen in den Zellen nicht nur abgelagert, sondern auch abnorm lange festgehalten und angehäuft wird". Die Zellen vermöchten also das normalerweise angebotene Eisen nicht mehr zu verarbeiten und abzugeben, sondern es bleibt in den Zellen liegen. Die Schädigung betrifft vor allem die Epithelien von Leber, Pankreas und Speicheldrüsen, aber auch die Zellen des reticulo-endothelialen Stoffwechselapparates. In unserem Falle sind 
allerdings die Milz und die übrigen Lymphdrüsen relativ gering mit Pigment beladen und stehen dadurch in markantem Gegensatze zu den retroperitonealen Drüsen, die durch ihren enormen Pigmentgehalt tief rostbraun gefärbt sind. Dies zwingt uns dazu, neben einer Schädigung der Reticulo-endothelien im Sinne Lubarschs für letztere Drüsen noch eine starke Zufuhr von Eisen in irgendwelcher Form von den in ihrem Einzugsgebiet liegenden parenchymatösen Organen, also aus Leber und Pankreas, auf dem Lymphwege anzunehmen. Wir denken. dabei namentlich an Zufuhr von fertigem Pigment durch siderofere Zellen oder an Zufuhr eisenhaltiger Gewebssäfte. Dadurch läßt sich der enorme Pigmentgehalt der Lymphdrüsen ungezwungen erklären. Die Zufuhr eisenhaltiger Gewebssäfte und das Freiwerden von Pigment innerhalb der Lymphdrüsen durch Zugrundegehen der mit demselben übermäßig beladenen Zellen führen ihrerseits zur Adsorption von Eisen in die Gitterfasern und zu einer schließlichen Inkrustation der letzteren mit Eisensalzen, worauf auch noch eine partielle Verkalkung folgt.

Die breiten, hyalinen Balken endlich, die sich stellenweise dem eisenhaltigen Gitterwerk aufs engste angelagert haben, betrachten wir als eine nachträgliche, nach der Inkrustation des letzteren erfolgte Bildung. Die inkrustierten Balken scheinen auf das in den Maschen liegende Gewebe einen gewissen Reiz auszuüben, worauf letzteres mit der Ablagerung von conjunctivalem Hyalin auf das eisen- und kalkhaltige Reticulum antwortet.

Fall 2: Struma nodosa parenchymatosa et cystica. J. Nr. 1844, 1921.

Der zweite Fall unserer Beobachtungen berieht sich auf Befunde in einer Struma eines 21 jährigen Mannes. Bei der Operation fand sich im rechten Lappen am untern Pol eine kleinfaustgroße Cyste mit etwa $80 \mathrm{ccm}$ bräunlichem dickflüssigem Inhalt. Vom linken Lappen wurden mehrere kleine, solide Knoten bis zu 1,5 cm Durchmesser entfernt. Das Material gelangte sogleich nach der Operation auf der hiesigen chirurgischen Klinik in unser Institut, wo ich sofort nach kurzem Kochen in absolut eisenfreiem, destilliertem Wasser Gefrierschnitte anlegte und mit denselben die Eisenreaktion mit absolut eisenfreien Reagenzien ausführte. Es handelt sich hier also um denkbar frisch untersuchtes Material. Daneben wurden auch Stücke in Formalin eingelegt und in Celloidin eingebettet.

Der mikroskopische Befund der soliden Knoten ist der einer Struma nodosa parenchymatosa mit teils sehr dichtstehenden, schmalen, soliden Strängen epithelialer Zellen, mit hellem Protoplasma und bläschenförmigen Kernen, auch findet sich hier und da beginnende Bläschenbildung. Im Zentrum der Knoten zum Teil reichlich hyalines Bindegewebe und kleine Kalkherde.

Die näher zu schildernden Veränderungen fanden sich aber in der Wand des cystischen Knotens. Dieser bietet makroskopisch folgenden Befund: Der cystische Hohlraum mißt 3-4 cm im Durchmesser, die Wandung ist ziemlich derb und mißt 


\section{H. Schuppisser: Über Eiseninkrustation der Bindegewebssubstanzen}

0,5-1 cm in der Dicke. Die glatte Innenfläche ist blutig verfärbt und enthält kleine punkt- oder streifenförmige Einsprengungen von eigentümlich rostbrauner Farbe, da neben auch kleine, weiße, glänzende Sprenkel (Cholestearin).

Das mikroskopische Bild ist folgendes:

In dex Wand des eystisehen Knotens findet sich Adenomgewebe mit kleinen bis mittelgroßen, leeren Bläschen, mit hellem, kubischem oder niedrigzylindrischem Epithel. Die Bläschen reichen jedoch nur selten bis an die Innenfläche der Wandung, sondern werden nach innen zu kleiner und spärlicher, erscheinen komprimiert und atrophisch, indem zwischen ihnen ein aus breiten, hyalinen Balken bestehendes Bindegewebe auftritt. Die Bläschen treten schließlich meist ganz zurück, so da $\beta$ die Innenfläche der Cyste von einem bald schmäleren, bald breiteren Gewebe aus dicht zusammenliegenden, hyalinen Balken besteht, zwischen welchen nur schmale Spalträume übrigbleiben, in welchen zum Teil schmale, spindelförmige Zellen liegen. An vielen Stellen fehlen zellige Elemente vollkommen. Die Balken verlaufen meist parallel zur Oberfläche. An anderen Stellen folgt auf das Follikelgewebe ein lockeres, weitmaschiges Bindegewebe mit schmalen, collagenen Fibrillen und ziemlich zahlreichen, spindelförmigen Bindegewebszellen. In den breiten Spalträumen liegen oft vereinzelte Lymphocyten, ferner losgelöste bindegewebige Zellen, an mehreren Stellen auch sehr zahlreiche, aus ihrem Verbande gelöste, große, helle Drüsenepithelien, die, den Gesetzen den Oberflächenspannung folgend, eine rundliche Gestalt angenommen haben. Hier finden sich auch zahlreiche, weite Capillaren, in welchen ab und zu neutro- und eosinophile Leukocyten anzutreffen sind. An wenigen Stellen haben auch frische Blutungen stattgefunden. Von diesen locker aufgebauten bindegewebigen Partien zu dem kernlosen, hyalinen Gewebe finden sich überall fließende Ubbergänge. In den hyalinen Partien fehlen die Gefäße oft auf weiter Strecke, die noch erhaltenen zeigen ein enges Lumen und eine stark verdickte, aus konzentrisch angeordneten, hyalinen Balken bestehende Wandung. Ab und zu trifft man aber noch auffallend weite, mit Erythrocyten prail gefüllte Capillaren.

Die Cystenwand ist nun einmal ausgezeichnet durch großen Gehalt an bräunlichem Pigment, und zwar findet sich dieses oft in Form sehr feiner, dunkelbrawner Körnohen im Epithel zahlreicher Follikel und ist hier in den Zellgranula aufgespeichert, ferner in den großen, frei in den Gewebsspalten liegenden Epithelien als größere, dunkelbraune Körner, die oft in großer Zahl in den Zellen anzutreffen sind. Auch liegt das Pigment in den fixen oder losgelösten Bindegewebszellen ebenfalls in Form sehr feiner, rundlicher Körner oder als gröbere Körner. Schließlich liegen in den schmalen Spalträumen zwischen den Fibrillen oft freie, große, eckige, dunkelbraune Pigmentschollen. Bei der Färbung mit Schalachrot erweist sich das Epithel zahlreicher Follikel als mit feinen Fetttröpfchen erfiullt, ebenso zahlreiche, spindelförmige Bindegewebszellen, während die losgelösten Epithelien vorwiegend mit großen Fetttropfen angefüllt sind. Im Zentrum der breiten, hyalinen Balken sind oft feine Fetttröpfchen eingesprengt. An einigen Stellen, namentlich da, wo der Aufbau in Follikel gestört ist und die Epithelien ein wirres Durcheinander bilden, sind große Cholestearinkristalle eingelagert, die von Fremdkörperriesenzellen umschlossen sind.

Nahe der Innenfläche des cystischen Raumes zeigt sich nun eine auffallende Veränderung: An vielen Stellen treten bei der Hämalaun-Eosinfärbung in den homogenen, blaßrot tingierten hyalinen Balken dunkelblaue, manchmal fast schwarze Verfärbungen der Grundsubstanz auf, die sich oft in ausgedehntem Maße in ganz unregelmäßiger Ausbreitung vorfinden. Die dunkelblau gefärbten. Fasern bilden zum Teil in dichter Lagerung breite Bündel, die bei schwacher Vergrößerung mit ihrer feinen Strichelung an eine Federzeichnung erinnern, während bei starker Vergrößerung die dunkelblauen Fasern an zahlreichen Stellen wie zerbrochen ausseben. Neben 
den Bündeln parallel verlaufender Fasern finden sich aber auch Anhäufungen von ganz wirr durcheinander verlaufenden Fasern, einem unregelmäBigen Astwerk mit zahlreichen Bruchstücken vergleichbar. An einigen Stellen häufen sich die blauen Fasern zu größeren, länglichen oder rundlichen Konglomeraten an, welche bei schwacher Vergrößerung fast homogen erscheinen können und nach außen durch blaBrot gefärbte Bindegewebsstreifen scharf abgegrenzt sind. Neben diesen gestreckt oder unregelmäBig verlanfenden blauen Balken sind solche zu erwähnen, die kleine Ringe oder Ovale darstellen und, wie bei starker Vergrößerung erkenntlich, ein mit Endothel ausgekleidetes, meist spaltförmiges Lumen umgeben, in welohem zum Teil

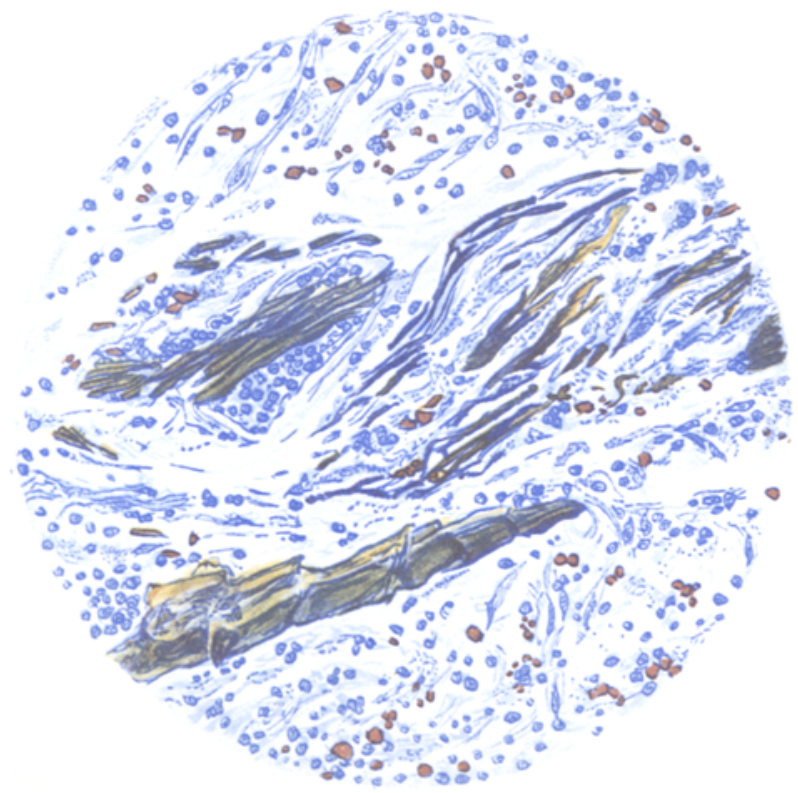

Abb. 2. Schnitt aus den innern Teilen des cystischen Strumaknotens (Fall 2). Leitz Obj. 7, Ok. 1. Färbung mit Hämalaun. Grünliche oder gelbliche Eisenkonkretionen, links oben von Riesenzellea amschlossen. Rechts ist das Hervorgehen von Konkrementen aus eisenhaltigen, blaugefärbten, hyalinen Balken ersichtlich. Hämosiderinschollen dunkelbraun. In der Grundsubstanz eingelagert mäßig zahlreiche Bindegewebszellen und Lymphocyten.

noch Erythrocyten sichtbar sind. Es handelt sich also um blaugefärbte, hyalin degenerierte GefäBwände. Diese blaue Verfärbung ist verschieden weit ausgedehnt, indem sich oft Riage von mehreren konzentrisch angeordneten, blanen Balken vorfinden, oder die Blaufärbung umgibt das Lumen nur auf der einen Seite. An anderen Stellen liegen kleinere, ovale Gebilde vor, die aus einem hyalinen, breiten, bandartigen Balken bestehen, der ein spaltförmiges Lumen nmgibt, offenbar hyalin verdickte Membranae propriae von zugrunde gegangenen FollikeIn. In Adenomen der Schilddrüse kommt es nämlich nicht selten zur Ausbildung einer Membrana propria, während eine solche den Bläschen der normalen Schilddrüse fehlt (Wegelin). In diesen hyalinen Membranen hat sich nun ebenfalls die Blaufärbung in ganz verschiedener Extensität festgesetzt.

Was uns aber in dieser Struma speziell anffällt, ist folgende interessante Erscheinung: Die dunkelblau verfärbten, teils noch intakten, teils bereits wie zerbrochen aussehenden hyalinen Fasern gehen in ganz scharf konturierte, durch- 


\section{H. Schuppisser: Über Eiseninkrustation der Bindegewebssubstanzen}

sichtige, helle Gebilde über, die meist anfangs noch leicht bläulich verfärbt sind, dann aber immer mehr den blauen Farbenton verlieren und in vollkommen durchsichtige, glashelle Gebilde von leicht grünlicher oder yelblicher forbe übergehen (Abb. 2). Es entstehen so aus den blauen Balken sehr scharfkantige, ganz isoliert im Gewebe liegende, kleinere Körner und Schollen, die oft anfangs noch dicht gelagert sind und den Verlauf der Faser fortsetzen, dann aber sicb immer mehr aufsplittern. An anderen Stellen gehen aus den blauen Balken längere, stäbchen- und spießförmige, ebenfalls scharf konturierte Gebilde von hellgrüner oder hellgelber Farbe und glasartiger Durchsichtigkeit hervor, wobei die Enden der hyalinen blaven Balken, bevor sie in die stäbohenartigen Fragmente zerfallen, bereita stark anfgehellt, etwas durchsichtig und starr gestreckt erscheinen. Oft zeigen sehr breite, parallel verlaufende Bündel solcher blauer, hyaliner Fasern diesen Übergang in helle, starre Bälkchen von grünlicher Farbe, die dann parallel verlaufend, förmliche Garbenbündel bilden. Diese enden nach kürzerem oder längerem Verlauf ziemlich scharf und sind allseitig von eosinroten oder blaugefärbten hyalinen Balken umgeben. An anderen Stellen bilden solche Bündel von hellen Bälkchen, Spießen und Schollen ein wirres Durcheinander, auch zeigen sie in unregelmäBiger Weise wieder blaue Verfärbungen und Übergänge in blaue Fasern. Ganz selten scheinen auch helle, körnige Gebilde direkt aus den eosinrot gefärbten Balken der Grundsubstanz hervorzugehen. Oft zeigen sich auch im Verlaufe der blauen Balken durchsichtige, mehr oder weniger aufgehellte Partien, ohne daß sich die Balken aufzusplittern brauchen. Auch sieht man oft kleinere und größere, unregelmäßig gestaltete Gefüge soleher kleiner, scharfkantiger, hellgrüner Schollen und Stäbchen, die ganz zusammenhanglos im Gewebe eingelagert sind, also kein Hervorgehen aus der hyalinen Substanz mehr erkennen lassen. Zum Teil liegen solche Gefüge auch in ziemlich kernreichen Partien. In besonders auffälliger Art finden sich, namentlich in den innersten Schichten der Cystenwand, isolierte, sehr breite und lange, scharfkantige, glasartige Balken (Abb. 3). Diese lassen bei starker Vergrößerung jedoch meist längsverlaufende Spalten erkennen, so daß sie aus parallel angeordneten, feineren Balken zusammengesetzt erscheinen. Andere dieser großen Konkremente sind durch quere und schräge Frakturlinien in rhombische oder annähernd quadratische Teilstücke zergliedert (Abb. 2). Die endständigen Bruchstücke laufen oft zugespitzt aus. Die Balken zeigen stellenweise, namentlich an den Enden, eine bläuliche Verfärbung. In einigen Schnitten erhält das histologische Bild durch das reichliche Vorhandensein dieser großen, balkenartigen Konkremente, die in regelloser Anordnung in der eosinrot- oder blaugefärbten Grundsubstanz liegen und von derselben durch ihr durchsichtiges, gelbes Aussehen kontrastieren, ein eigenartiges Aussehen. Hervorzuheben ist noch, daß diese Konkremente, vorzüglich die großen, von Fremdkörperriesenzellen umgeben sind, die ihnen kappenförmig aufsitzen oder sie vollkommen umhüllen. Oft sieht man zwischen dem Protoplasmaleib der Riesenzellen und den scharfrandigen Konkrementen einen feinen, hellen, spaltförmigen Zwischenraum. Bei genauem Zusehen finden sich solche größere und kleinere Riesenzellen sehr häufig vor, zum Teil auch an den blauen, starren, hyalinen Balken. Oft schließen die Riesenzellen ganze Gefüge aus kleinen Körnern und Schollen in sich ein. Hier noch einige Größenangaben. Die kleinsten Splitter und Körner haben eine Länge von $2-5 ! \mu$ und eine Breite von $1--2 \mu$. Die letztgenannten, großen, balkenartigen Konkremente weisen eine Länge von 12-50 $\mu$ und mehr auf und eine Breite von 4-10 $\mu$. Das längste Konkrement, das wir zu Gesichte bekamen, besitzt die respektable Länge von $250 \mu$ und eine Breite von $20 \mu$, allerdings ist es durch quere Frakturlinien in mehrere Stiucke zerlegt.

Beachtenswerte Verhältnisse bieten auch die Gefäßwände, indem auch hier die konzentrisch angeordneten, blauen, hyalinen Fasern nach außen oft in grünliche, 
transparente Balken oder feinere, nadelförmige Gebilde, ebenfalls von glasartigem Aussehen, ïbergehen, welche in dichter, konzentrischer Anordnung gelagert sind. Im Innern dieser Gefäße sieht man oft noch deutlich ein Endothel und ein Lumen mit gutgefärbten Erythrocyten. So bilden sich in den Gefäßwänden Halbkreise oder Kreise von solchen Konkrementen aus. Oft sind hier keine hyalinen. Balken mehr sichtbar, sondern nur noch die schalenförmig angeordneten Konkremente, die Fragmente von Ringen darstellen. Das Lumen ist dann meist obliteriert. Vielfach ist außer sichelförmig angeordneten Konkrementen nichts mehr von der Gefäßwand zu erkennen. Auch die Membranas propriae von untergegangenen Follikeln können in Konkremente umgewandelt sein.

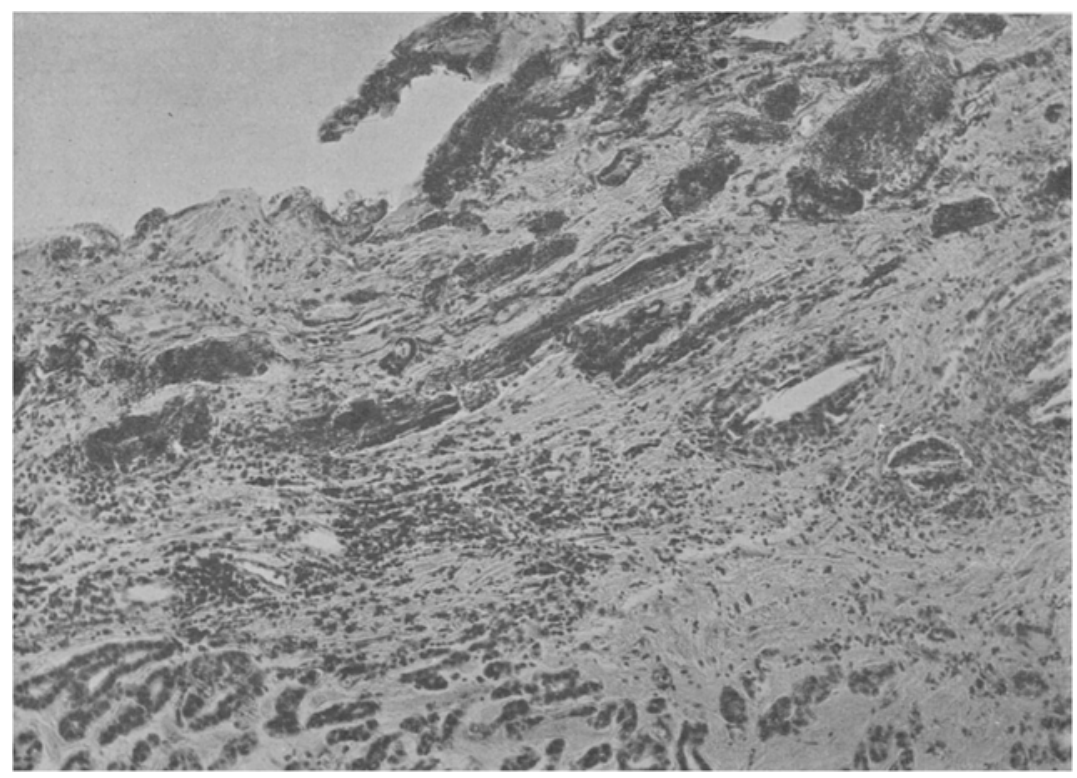

Abb. 3, Schnitt von der Innenfläche des cystischən Strumaknotens (Fall 2), Vergrößerung 80 fach. Färbung mit Hämalaun-Eosin. Dunkelgefärbte Eisenkonkretionen, $z$. T. mit feiner Längsstreifung, stellenweise von Fremdkörperriesenzellen umschlossen. Unter rechts von Cholestearinkrystallen herrührende helle Lücken, ebenfalls von Fremdkörperriesenzellen umgeben.

Die Färbung nach van Gieson ergibt ebenfalls schöne und eindeutige Bilder, indem sich in der Cystenwand die bei der Hämalaunfärbung hellgrün oder hellgelb erscheinenden Konkremente ebenfalls nicht gefärbt haben und, zwischen den dunkelgefärbten Riesenzellen gelagert, durch ihr blaßgelbes bis hellgelbes, transparentes Aussehen besonders schön hervortreten. Hier und da finden sich in ihnen aber auch blaurot verfärbte Partien. Das hyaline Gewebe hat sich hier ebenfalls teils rot gefärbt, teils blaurot bis dunkelblau, wobei letztere Partien den Stellen mit blauer Färbung bei Hämalaunfärbung entsprechen. Auch hier läßt sich vielerorts ein Hervorgehen der Konkremente aus blau verfärbten Partien der Grundsubstanz erkennen. Das früher erwähnte Pigment zeigt auch hier eine gelbbraune bis tiefbraune Farbe.

Im ungefärbten Präparat fallen die Konkremente ebenfalls durch ihre scharfen Konturen, durch starkes Lichtbrechungsvermögen sowie durch einen blaßgrün- 


\section{H. Schuppisser : Über Eiseninkrustation der Bindegewebssubstanzen}

lichen Farbenton auf. Demgegenüber erscheinen die im Hämalaunpräparat tiefblau gefärbten Partien hier bedeutend blasser und es fehlt die scharfe Konturierung, jedoch sind sie von den gewöhnlichen hyalinen Balken deutlich durch stärkeren Glanz ausgezeichnet und erscheinen oft fein gekörnt. Im. Polarisationsmikroskop ist außer an den Cholestearinkrystallen und an sehr spärlichen Fetttropfen nirgends Doppelbrechnung zu konstatieren. Die Konkremente sowohl wie die blauen Balken verhalten sich vollkommen negativ.

Die Konkremente sind unlöslich in Alkohol und Äther, auch in Alkalien, leicht löslich dagegen in verdünnten Säuren. Dann wurden namentlich histochemische und färberische Methoden zur Prüfung eines evtl. Kalkgehaltes der Konkremente ausgeführt. Das Verhalten der letzteren verdünnter Salzsäure und verdünnter Schwefelsäure gegenüber ließ sich unter dem Mikroskop recht gut verfolgen und ergab folgenden Befund: Mit verdünnter Salzsäure lösen sich die Konkremente in einer Zeit von 30-60 Minuten vollständig auf, obne daß irgendwelche Gasbildung eintritt. Beim Durchziehen von verdünnter Schwefelsäure unter dem Deckgläschen verschwinden die Konkremente nach kurzer Zeit restlos, ohne daß sich je ein Aufschießen von Gipskrystallen feststellen ließe, auch nicht, wenn man zuvor den Schnitt in $40 \%$ Alkohol unter das Deckglas bringt. Auch bei Auflösen der Konkremente in Salzsäure und nachherigem Zusatz von oxalsaurem Ammonium zeigt sich nie eine Ausscheidung von Calciumoxalatkrystallen. Auch an den blauen Partien der Grundsubstanz fallen diese Kalkproben vollständig negativ aus. Die Anwendung der $v$. Kossa schen Silberreaktion ergibt folgendes: Weitaus die Mehrzahl der Konkremente bewahrt ihr transparentes, hellgrünes Aussehen, nur ganz vereinzelte Konkremente zeigen im Innern dunkelbraune oder schwarze Stellen. Auch die Roehlsche Methode zum Kalknachweis, die allerdings keine sicheren Befunde zu liefern vermag, ergab immer vollkommen negative Ergebnisse. Ohne Behandlung mit Oxalsäure färbten sich bei dieser Reaktion die Konkremente allerdings intensiv blauschwarz, was auf ihren Eisengehalt hindeutet.

Die Eisenreaktionen lassen denn auch eine ganz ausgedehnte Ablagerung von Eisen im Schnitte nachweisen. Mit Schwefelammonium färben sich nämlich alle im Hämalaunpräparat blaugefärbten Partien des Bindegewebes hellgrünlich bis vollkommen schwarz. Die Konkremente, ebenso alles Pigment, sind ebenfalls schwarz gefärbt. Bei der Berlinerblaureaktion färben sich in der Grundsubstanz ausgedehnte Partien schwach bläulich bis tiefblau. Das Pigment ist größtenteils blau gefärbt, zum Teil aber auch nur hellgrün, zahlreiche Körner sind noch braun gefärbt. Auch die im Epithel der Bläschen angetroffenen feinen, bräunlichen Körner sind blau gefärbt, zum Teil weist zudem das Protoplasma der Zellen eine leichte, diffuse Blaufärbung auf. An Serienschnitten läßt sich ferner genau zeigen, daß die Konkremente sich meist intensiv blau gefärbt haben, jedoch nicht durchwegs, indem man ganz selten noch auf vollkommen helle Konkremente stößt. Ferner sind zahlreiche Konkremente nur blaBblau gefärbt. Die Riesenzellen treten bei Kontrastfärbung mit Carmin sehr schön hervor und bilden zusammen mit den schön blau gefärbten Balken farbenprächtige Bilder. Einen Eisengehalt lassen die Riesenzellen vermissen. Durch sehr schöne Blaufärbung treten auch die konzentrisch angeordneten Konkremente hervor; ihre Blaufärbung ist aber oft auch unvollkommen. Bei der Turnbullreaktion fällt die Blaufärbung viel vollständiger aus, indem sämtliches Pigment sich sattblau gefärbt hat, ebenso sind nun alle Konkremente gleichmäßig tief blauschwarz. Die Überlegenheit dieser Eisenreaktion gegenuiber der Berlinerblaureaktion zeigt sich hier deutlich.

Um die Frage entscheiden zu können, ob evtl. Fettsäuren oder Seifen am Aufbau der Konkremente beteiligt sind, wurden die von Fischler angegebenen Reaktionen ausgeführt. Sie fielen aber vollkommen negativ aus. Bei der Färbung mit 
Nilblausulfat treten nur an wenigen Stellen in den hyalinen Balken leichte violette Verfärbungen zutage.

Die Elastinfärbung fiel vollkommen negativ aus, auch an den konzentrisch geschichteten Konkrementen der Gefäßwände, wo nirtgends ein Übergang in elastische Fasern sich konstatieren ließ. Die Cystenwand ist überhaupt äußerst arm an elastischen Elementen. Da also nur die Eisenreaktion an den Konkrementen positiv ausfiel, interessierte uns noch die Frage, was denn überhaupt nach der Entziehung des Eisens aus dem Schnitte von den Konkrementen noch übrigbleibe. Zu diesem Zwecke färbte ich von Serienschnitten zuerst einen Schnitt mit HämalaunEosin, die anderen legte ich in konzentrierte Oxalsäure bei Brutofentemperatur, bis die Eisenreaktion vollständig negativ ausfiel (mindestens 1 Stunde). Dann färbte ich die Schnitte wieder mit Hämalaun und nach van Gieson. In diesen Schnitten sind die. Konkremente nun vollständig verschwunden. Durch Vergleich der Schnitte läBt sich feststellen, daß da, wo die Konkremente lagen, nach dem Entzug des Eisens manchmal scharf konturierte Lücken entstehen, welche namentlich schön im Protoplasmaleib von Riesenzellen zu sehen sind. An anderen Stellen jedoch zeigt sich, daß nach der Entziehung des Eisens die Konkremente eine homogene oder ganz feingekörnte Grundsubstanz besitzen, die sich bei Hämalaun-Eosinfärbung ganz blaßrot färbt, nach van Gieson etwas stärker rot. Die Blaufärbung der faserigen Grundsubstanz ist nach der Oxalsäurebehandlung völlig verschwunden. An ihrer Stelle liegen hyaline Bälkchen, die mit Eosin sich blaßrot, nach van Gieson sich größtenteils rot färben und nur stellenweise noch einen ganz leicht bläulichen Ton annehmen. Allerdings lassen sich die hyalinen Balken oft in ganz feine Fäserchen auflösen, die auf dem Querschnitt als feinste Kömchen erscheinen.

Fall 3: 'Struma nodosa parenchymatosa et colloides. J. Nr. 625, 1921.

Der dritte Fall unserer Untersuchungen betrifft ebenfalls Befunde in einem Kropf eines 21 jährigen Mannes mit Anzeichen von Hypothyreoidismus. Bei der Operation wurden mehrere bis zu 2,5 cm große Knoten entfernt. Unser Interesse beansprucht ein $2 \mathrm{~cm}$ großer Knoten, der auf dem Schnitt von mehreren kleinen Cysten durchsetzt ist und zahlreiche weißliche, glänzende und braunrötliche, rostfarbene Einsprengungen enthält. Das Material wurde rasch in Formol fixiert, zum Teil in Celloidin eingebettet, zum Teil auf dem Gefriermikrotom geschnitten.

Ich lasse hier die Beschreibung des Hämalaun-Eosinpräparates folgen. Der Knoten wird von einer dünnen Bindegewebskapsel begrenzt und besteht aus meist sehr dichtliegenden, kleinen und mittelgroßen Bläschen und zahlreichen, zum Teil verzweigten Schläuchen mit ziemlich hohem, hellem, zylindrischem Epithel. Letzteres bildet oft papillen- oder polsterförmige Wucherungen. Die Lumina sind meist leer oder enthalten dünnflüssiges, eosinophilesKolloid. Das Bild erinnert stark an eine basedowifizierte Struma nodosa, obschon klinisch mehr die Zeichen einer Hypothyreose vorliegen. Das Stroma ist meist spärlich, ziemlich gefäßreich, im Zentrum etwas reichlicher und ödematös, doch finden sich hier und da fibröse Partien, die nur sehr spärliche atrophische Bläschen enthalten.

Das Bild des Knotens wird nun einmal beherrscht von zahlreichen Blutungen. Solche finden sich in zahlreichen Follikeln, die dadurch oft erweitert sind, hier und da auch durch Einreißen der Septen konfluieren. Sie enthalten neben Erythrocyten desquamiertes Epithel. Zahlreiche kleinere Blutungen liegen im Stroma, dann aber ist der Knoten von mehreren ganz ausgedehnten Blutungen durchsetzt, in deren Bereich die Gewebsstruktur vollkommen zerstört ist und Epithel- und Bindegewebs- 


\section{H. Schuppisser: Über Eiseninkrustation der Bindegewebssubstanzen}

zellen ein wirres Durcheinander bilden. Hier liegen auch zahlreiche Cholestearinkrystalle, umgeben von Riesenzellen, auch enthalten sehr zahlreiche Epithel- und Bindegewebszellen reichlich feintropfiges Fett. Namentlich in den bluthaltigen Follikeln bildet das Epithe bei Scharlachfärbung schöne rote Säume. Als weitere Folge der Blutung hat sich in den Zellen sehr reichlich Hämosiderin gebildet, dieses liegt sowohl im wandständigen Epithel uud ist hier sehr feinkörnig, als anch im desquamierten Epithel und in den Bindegewebszellen. In den fibrösen Partien ist das Pigment auch grobschollig im Interstitium abgelagert. Vielfach kommt Fett und Hämosiderin gepaart in den Zellen vor. An einigen Stellen trifft man auch geringe Entzündung in Form von Infiltration mit neutro- und eosinophilen Leukocyten, Lymphocyten und Plasmazellen.

Ein ganz besonderes Gepräge erhält aber das mikroskopische Bild durch gewisse, die kollagene Substanz betreffende Veränderungen, die sich gemäß den nachherigen Untersuchungsergebnissen als Inkrustation mit Eisen erweisen. Da finden sich einmal an den durch Blutung zertrümmerten Gewebsstellen zahlreiche, schwachblan bis tiefblau gefärbte kollagene Fibrillen, die hier und da einen Übergang in blaßblaue, durchsichtige, starre Balken mit scharfer Konturierung aufweisen. Des weiteren finden sich zwischen den Erythrocyten und den Gewebszellen liegend bald isoliert, oder zu kleinen, unregelmäßigen Gefügen zusammengelagert, scharf konturierte, eckige Bröckel oder schmale spieß- oder stäbchenartige Gebilde von glasartigem Aussehen und hellgrüner oder hellgelber Farbe. Thnen haben sich oft Fremdkörperriesenzellen angelagert. Neben diesen kleineren Gebilden sieht man auch größere Klumpen, die zum Teil unregelmäßig ausgezackt sind und durch massives Aussehen imponieren. Sie zeichnen sich durch die gleichen Eigenschaften aus und sind noch häufiger von Fremdkörperriesenzellen umschlossen. Öfters sieht man auch ringförmige, einen kleinen Kreis oder Kreisfragmente bildende, scharf konturierte, hellgrïne Bälkchen, auch in auffallender Weise vollkommen parallel verlaufende Balken, die zum Teil tiefblau, zum Teil auch blaBblau oder vollkommen hell und kristallartig aussehen. Diese Gebilde sind zweifellos veränderte Wandungen von Capillaren oder kleineren Gefäßen. Nicht selten sieht man größere Gefäße, die im Lumen noch Erythrocyten enthalten und deren Endothel noch deutlich erhalten ist, die aber an Stielle der normalen Wandung aus mehreren konzentrisch angeordneten blauen Balken bestehen. Ich will gleich anfügen, daß sich in diesen so veränderten Gefäßwänden nirgends elastische Fasern nachweisen lassen.

Ganz gleichartige Veränderungen prägen den fibrösen Partien, welche teils in der Nachbarschaft der Blutungen, teils in größerer Entfernung von denselben liegen, ihren Stempel auf. In den kollagenen Balken treten oft, ganz allmählich an Intensität zunehmend, blaßblaue bis tiefblaue Verfärbungen auf. Oft sind ganze Bündel in diesem Sinne verändert, das Bild ist dann am ehesten mit parallelen Federstrichen zu vergleichen. Besonders schön zeigt sich auch hier, wie oft aus den blauen Balken eckige Körner und Stäbchen von stark transparentem, wiederum leicht grünlichem oder gelblichem Aussehen hervorgehen. Diese scharfrandigen Gebilde scheinen dann förmlich aus dem Verband mit der zugehörigen Faser herausgebrochen zu sein und liegen vollkommen isoliert im Gewebe. Neben den hellen Konkrementen sind solche zu nennen, die das Hämalaun noch sehwach angenommen haben. Hier und da erscheinen auch im Verlaufe der Fasern selbst helle, durchsichtige Partien von starrem Verlauf. Die glasartig aussehenden Balken bilden oft ganze Bündel. $\mathrm{Ab}$ und zu liegen auch größere, unregelmäßig geformte Konglomerate aus kleineren und größeren Schollen im Gewebe, entweder zwischen blauen Fasern liegend oder zwischen eosinrot gefärbte Grundsubstanz gelagert. Zu erwähnen ist noch, daß auch hier oft die in den Blutungsherden hervorgehobenen Veränderungen von Gefäßwänden sich vorfinden, ferner daß die Konkremente oft von Riesenzellen umgeben sind, seltener auch blaugefärbte, dicke Fibrillen. 
Ich habe an den genannten Gebilden sämtliche färberischen und chemischen Untersuchungen wie im Falle 2 ausgeführt und habe, wie das nach dem morphologisehen Aussehen der in diesem Falle beschriebenen Konkremente zu erwarten war, ganz die gleichen Resultate erhalten.

\section{Fall 4: Mitztumor bei Lymphogranulom.}

Die Milz stammt von einer im 47. Altersjahr verstorbenen Patientin. Laut Anamnese wurde die Milz mit Röntgenstrahlen intensiv bestrahlt und soll sich auf die Hälfte ihrer Größe reduziert haben. Die anatomische Diagnose (Sektions-Nr. 98, 1908) ist folgende: Lymphogranulom sämtlicher Lymphdrüsengruppen, Metastasen in Lungen, Leber, Nieren, Peritoneum, Knochenmark, Milz. Chronischer Milztumor, Ascites. Hydrothorax dexter, Anasarka beider Beine. Exzentrische Hypertrophie des rechten Ventrikels. Eitrige Bronchitis. Atelektase der rechten Lunge. Linksseitige Hydronephrose. Uteruspolyp.

Bei der Selation wiegt die Milz $1030 \mathrm{~g}$, mißt $17: 12: 10 \mathrm{~cm}$ und besitzt eine sehr derbe Konsistenz. Oberfläche glatt, Serosa zum Teil weißlich verdickt. Die Schnittfläche zeigt sehr zahlreiche Trabekel, in welchen sehr oft rostbraune Streifen von unregelmäBiger Form zu sehen sind. Die Pulpa ist dunkelrot, Follikel nicht sichtbar. Selten größere, graue, transparente Herde von 5-7 mm Durchmesser.

Mikroskopisch zeigt sich folgendes Bild: Die Trabekel sind stark verdickt und stehen in unregelmäBiger Weise mit schmälern oder breiteren, oft sehr ausgedehnten fibrösen Strängen in Verbindung, welche die Pulpa nach Art eines Netzwerkes durchsetzen und offenbar an die Stelle von Pulpagewebe getreten sind und zum großen Teil aus ziemlich zellreichem Bindegewebe bestehen. In Anlehnung an die Trabekel selten noch kleine Follikel. Die nicht narbig verödete Pulpa weist erweiterte und stark gefüllte Sinus auf, in den Maschen der Pulpa reichlich Erythrocyten, Lymphocyten und neutrophile Leukocyten. In einzelnen Pulpazellen spärliches Hämosiderin. An anderen Stellen ist die Pulpa zellärmer, sklerasiert und gebt dann ohne scharfe Grenze in die vollkommen fíbrös umgewandelten Stränge über. Die größeren makroskopisch granen Herde bestehen aus typischem Lymphogranulomgewebe mit zahlreichen Sternbergschen Piesenzellen, feruer enthält die Pulpa vereinzelte submiliare Tuberkel, zum Teil mit zentraler Verkäsung.

Die uns hier interessierenden Veränderungen liegen in dem an die Stelle von Pulpagewebe getretenen fibrösen Gewebe, in den Trabekeln und in der gleichmäßig bindegewebig verdickten Kapsel. An diesen Stellen findet sich stellenweise zwischen den breiten, kollagenen Fibrillen sehr reichlich Hämosiderin, teils intracellulär gelagert, zum Teil extracellulär in Form dicht zusammengelegener, grober Körner, die die Gewebsspalten zum Teil vollkommen ausfüllen. Im ganzen ist das Hämosiderin in Form kleiner Herde abgelagert. In diesen Herden sieht man bei Hämalaun- und van Gieson-Färbung in den fibrösen Partien der Pulpa und in den Trabekeln, spärlicher auch in der Kapsel, vielerorts in den hyalinen Balken eine bläuliche Verfärbung auftreten, die oft in intensive Blaufärbung übergeht. In der Nähe der blauen Balken finden sich oft hellgelbe, scharf konturierte, jeglichen Zusammenhang mit dem übrigen Gewebe entbehrende, spießförmige oder balkenförmige Gebilde, die oft deutlich aus den blauen Balken hervorgehen. Diese Konkremente sind sehr gut von Hämosiderin zu unterscheiden und sind oft von. Fremdkörperriesenzellen umgeben, seltener sind auch Riesenzellen den blauen Balken angelagert. 


\section{H. Schuppisser: Über Eiseninkrustation der Bindegewebssubstanzen}

Zwischen den blauen Balken und den Konkrementen findet sich hier und da ein zartes, feinmaschiges Netzwerk aus blauen bis schwarzen, gewundenen, zum Tejl auch frakturierten Fibrillen, welche teils zwischen, teils über die blauen Balken verlaufen. Ein gleiches, feines Gitterwerk von teils gestreckten, teils gewunden verlaufenden, meist schmalen, selten etwas breiteren Fibrillen sieht man oft in den inneren Teilen der Milzkapsel, in ungleicher Ausdehnung. In den Maschen liegen meist zahlreiche Erythrocyten und reichliches, meist extracelluläres Hämosiderin und nur spärliche zellige Elemente. Das feine Gerüstwerk ist hellblau bis tiefblau gefärbt, nur selten ist ein Übergang der blawen Fibrillen in etwas breitere, helle Bälkchen zu konstatieren; letztere sind teilweise von Riesenzellen umgeben. Durch die Maschen verlaufen auch, was sehr gut sichtbar ist, Bündel von kollagenen Fasern. Dies zeigt schon deutlich, daß das Netzwerk selbst nicht aus kollagener Substanz besteht; namentlich bei der van Gieson-Färbung ist dieses feine Gitterwerk, das die tiefroten, collagenen Balken umspinnt, scharf hervorgehoben. Selten sind im Bereiche der Gitterwerke auch die collagenen Balken zum Teil blau verfärbt. Die Elastinfärbung zeigt, daß es sich bei dem mit Hämalaun blau gefärbten Gitterwerke in der Kapsel und an den übrigen mit Hämosiderin überladenen Stellen um elastische Fasern handelt, was ich auch infolge des fein gewundenen Verlaxfes der Fibrillen vermutet hatte. Bei Elastinfärbung findet sich nämlich überall in den inneren Teilen der Kapsel das nämliche feinfaserige Reticulum. Bei dieser Färbung unterscheiden sich auch die Trabekel von den narbigen Pulpastellen durch viel reichlicheren Gehalt an elastischen. Elementen und durch regelmäßige Anordnung derselben, während in den fibrösen Partien der Pulpa elastische Elemente fast vollkommen fehlen.

Ein dritter, auffälliger Befund besteht in einer tiefen Blaufärbung der Blastica interna zahlreicher größerer Gefäße der Trabekel mit Hämalaun. Diese erscheint dann zugleich mäßig verdickt, starr gestreckt, oft ist sie auch frakturiert. Selten färbt sich außerdem in der Gefäßwand ein feinmaschiges Fibrillennetz intensiv mit Hämalaun.

Die blauen, kollagenen Balken und die aus ihnen hervorgehenden Konkremente sowie die mit Hämalaun blaugefärbten Teile des elastischen Faserwerks und die blaugefärbten Membranae elasticae internae der Gefäße geben sämtlich stark positive Eisenreaktion. Das feine Gitterwerk der elastischen Fasern in der Kapsel tritt namentlich bei der Schwefelammoniumreaktion, wo das übrige Gewebe ungefärbt ist, sehr prägnant hervor. Einen Kalkgehalt der eisenhaltigen, kollagenen oder der elastischen Teile habe ich weder chemisch mittels der Kalkreaktionen noch färberisch nachweisen können.

Wir beschränken uns in der hier folgenden Besprechung vorläufig auf die Befunde in den beiden Strumaknoten und werden später noch auf die Veränderungen in der Milz zurückkommen.

In den Strumaknoten sind die uns hier interessierenden pathologischen Prozesse gleicher Natur, sodaß wir die Besprechung derselben zusammenfassen. Wir finden also in den durch Blutungen and regressive Erscheinungen verschieden stark veränderten Knoten eine ganz außergewöhnlich reichliche Ablagerung von histochemisch nachweisbarem Eisen. Dieses tritt auf erstens in Form des bräunlichem Pigments, das wir dem beschriebenen Verhalten gemäß dem Hämosiderin zuzählen, zweitens findet sich reaktionsfähiges Eisen in ausgedehntem Maße in den hyalinen Balken in diffuser Weise abgelagert, 
eine blaue bis schwärzliche Färbung derselben im Hämalaunpräparate hervorrufend. Diese Art von Eisenablagerung, welche auf den ersten Blick an Verkalkungen erinnert, ist ja recht häufig. Bemerkenswerterweise findet sie sich auch in den hyalin degenerierten Gefäßwänden und Membranae propriae untergegangener Follikel. Drittens endlich erscheint das Eisen in einer ganz ungewöhnlichen Form der Ablagerung, nämlich in. Form von festen Gebilden, die durch ihre hellgrüne bis hellgelbliche Farbe, durch ihr stark transparentes Aussehen und ihre scharfe Konturierung charakterisiert sind. Sie wechseln in Form und Größe von kleinen Splittern und Bröekelchen bis zu großen Balken. Auf Grund ihrer wechselnden Gestalt sowie des Fehlens der Doppelbrechung können wir sie nicht den Krystallen zurechnen, sondern wir müssen sie als Konkremente betrachten. Daß diese Konkremente nur Eisen und keinen Kalk enthalten, beweist der Ausfall der Kalkproben. Die einfachen histochemischen Proben mit Salzsäure und Schwefelsäure fielen konstant negativ aus. Demgegegenüber fällt die an den Konkrementen nux zum Teil sichtbare Braun- und Schwarzfärbung nach Kossa für einen Kalkgehalt nicht ins Gewicht. Es scheint uns aber sehr wahrscheinlich, daß dieser Ausfall der Silberreaktion durch die Anwesenheit von Phosphaten bedingt ist, mit welchen ein Teil des Eisens jedenfalls eine Bindung eingegangen ist.

Nach Auflösung der Konkremente bleiben zum Teil Fasern und hyaline Balken zurück, die sich nach van Gieson blaßrot färben und die wir demnach als Reste der kollagenen Substanz deuten, in welche hinein die Ablagerung des Eisens erfolgt ist. Das Hervorgehen der Konkremente aus stark mit Eisen imbibierten, durch das Hämalaun tiefblau gefärbten hyalinen Balken läßt sich ja vielerorts feststellen. Es ist anzunehmen, daß, wenn der Eisengehalt der kollagenen Fasern einen gewissen Grad überschreitet, dies zur Bildung der genannten Konkremente führt, die dann aus dem Verbande mit der kollagenen Faser herausgelöst werden. Die isolierten, scharfkantigen Konkremente besitzen vereinzelt noch bläuliche und nicht vollkommen transparente Stellen. Ein Hervorgehen der Konkremente durch massive Einlagerung in die hyalinen, kollagenen Balken wird besonders schön an den Gefäßwänden demonstriert, an welchen teilweise rote, eisenlose Balken, blaue eisenhaltige Balken und transparente Konkremente alle Übergangsstadien zueinander erkennen lassen. Wo ein solcher Übergang nicht ersichtlich ist, handelt es sich offenbar um ältere Konkremente, die durch den Umbau des Gewebes ihre Lage verändert haben. Dies scheint namentlich bei den sichelförmig angeordneten, als Überreste von Gefäßwänden imponierenden und bei den großen, balkenartigen Konkrementen oft der Fall zu sein.

Die Konkremente, die histochemisch nur aus Eisen bestehen und daneben noch eine kollagene Grundsubstanz aufweisen, sind wahr- 


\section{H. Schuppisser : Über Eiseninkrustation der Bindegewebssubstanzen}

scheinlich Ausflockungen von. Eisenhydroxyd. Herr Prof. Kohlschütter, Direktor des anorg.-chem. Laboratoriums in Bern, hatte die Freundlichkeit, meine Präparate anzusehen und sprach sich in diesem Sinne aus. Für Ausflockung spricht neben dem unregelmäBigen Aussehen der Konkremente namentlich die schalenförmige Ablagerung in Form von feinen Spießen und Bröckeln um einmal vorhandene Bildungen berum. Wir denken dabei namentlich an die konzentrischen Konkremente in und um Gefäßwände. Dies erklärt auch die Tatsache, daß sich nicht in allen Konkrementen eine kollagene Grundsubstanz nachweisen läßt.

Besonders hervorheben möchten wir noch die Tatsache, daß die Konkremente sehr oft die Bildung von Fremdkörperriesenzellen hervorgerufen haben. Dies zeigt, daß die Konkremente für das Gewebe nicht indifferent sind wie die Eisenablagerung in diffuser Form, sondern nach Art von Fremdkörpern reizend auf ihre Umgebung einwirken. Interessant ist, daß die Riesenzellen oft noch in sonst vollkommen zellfreien Partien anzutreffen sind. Vor allem aber geben uns diese Riesenzellen den wichtigen Beweis, daß die Konkremente intravital entstanden sind und keineswegs postmortale Ausfällungen darstellen, wie solche etwa durch Berührung mit den Fixierungsflüssigkeiten zustande kommen könnten.

Unsere Eisenablagerungen zeigen in ihrem färberischen Verhalten dem Hämalaun gegenüber mit den Kalkablagerungen weitgehende Ähnlichkeit, zum Teil aber verhalten sie sich abweichend. Der in diffuser Form abgelagerte Kalk reißt das Hämalaun gierig an sich, während die körnigen und eckigen Formen den genannten Farbstoff nur leicht und meist nur in den Randpartien annehmen. Unsere Eisenkonkremente zeigen hierin gegenüber den Kalkkonkrementen einen Unterschied, indem sie bei der gewöhnlichen Färbungsdaner das Hämatoxylin meist überhaupt nicht aufnehmen. Auch lassen sie sich sehr gut von den Kalkkonkrementen durch ihre hellgrüne oder hellgelbe Farbe unterscheiden, welch letztere an den Kalkkonkrementen nie vorhanden ist.

Besonders hervorheben möchte ich noch das Verhältnis der Konkremente zu den Hämosiderinschollen, die oft reichlich neben den Konkrementen liegen und oft die Größe von kleinern Bröckeln derselben besitzen. Die Unterscheidung ist aber meist leicht zu treffen, indem die Konkremente durch helles, glasartiges Aussehen und ihre scharfen, eckigen Konturen sich von den rundlichen, tiefbraunen, meist glanzlosen Pigmentschollen deutlich abheben. Nur an wenigen Stellen sah ich neben charakteristischen Pigmentschollen mehr eckige Gebilde von fast derselben Größe und Farbe, so daß ich über deren Zugehörigkeit zum Pigment oder zu den Konkrementen im Zweifel blieb. 
Jedenfalls zeigt sich auch im chemischen Verhalten eine weitgehende Verwandtsehaft der beiden Stoffe: Deutliche Eisenreaktion, bei der Turnbullreaktion vollständiger ausfallend als bei der Berlinerblaureaktion, Löslichkeit in Säuren, Unlöslichkeit in Alkalien. Der Unterschied liegt einmal in der Genese und im morphologischen Aussehen, chemisch bekundet er sich namentlich darin, daß bei Entzug des Eisens mit Oxalsäure die Konkremente viel rascher verschwinden, während noch sehr zahlreiche braune, eisenhaltige Pigmentschollen in unver. ändertem Zustande im Schnitte zu sehen sind. Das Eisen der Kon. kremente ist also den gewöhnlichen Reagenzien viel leichter zugänglich. Schließlich sei nochmals darauf hingewiesen, daß die Konkremente sehr oft von Fremdkörperriesenzellen umschlossen sind, was wir bei extracellulär gelagerten Hämosiderinschollen niemals beobachten konnten. Die Hämosiderinsehollen üben also keine oder doch eine viel geringere Reizwirkung auf das Gewebe aus.

Eine nähere Besprechung der Natur der blauen, kollagenen Fasern und der Konkremente in der Milz erübrigt sich, da wir sie nach ihrem morphologischen und chemischen Verhalten als die nämlichen Gebilde wie die hier besprochenen halten dürfen.

Die Genese der konkrementartigen Eisenablagerung in den Strumaknoten ist auf ihre intensive Durchblutung zurückzuführen, wodurch im erstbeschriebenen Knoten die große Cyste entstanden ist. Durch Zerfall der Blutkörper kommt es zu einer starken Überladung der Gewebssäfte mit gelöstem Eisen, was zur Aufnahme des letzteren in gelöster Form in die kollagene Substanz und zu nachträglicher Ausfällung führt. Als begünstigend für das Zustandekommen dieser Eiseninkrustation ist wohl der Umstand anzunehmen, daß die Säftezirkulation in den Knoten eine äußerst schlechte ist, besonders wenn noch durch Blutungen abnorme Druckverhältnisse geschaffen werden, so da $B$ die eisenhaltigen Flüssigkeiten sehr lange mit dem Gewebe in Kontakt stehen. Die reichliche Ablagerung von Fett und Cholestearin führen wir ebenfalls zum großen Teil auf aus dem Blut freigewordene Fettstoffe zurück.

Die Genese der Eisenablagerung in der Milz ist ebenfalls in frischen und älteren Blutungen zu erblicken, die zum Teil auf toxischen Einwirkungen beruhen dürften, zum Teil durch die Röntgenbestrahlung zu erklären sind. In den Blutungsherden dürfen wir ebenfalls eine mehr oder weniger starke Stagnation der entstehenden, eisenhaltigen Flüssigkeiten für das Zustandekommen der Konkremente verantwortlich machen. Für eine Störung im Abflusse des Saftstromes an den betreffenden Stellen ist die reichliche Neubildung von Bindegewebe und die infolge des Bestrahlens rasch eingetretene Schrumpfung des gesamten Organs zu verwerten.

Virchows Archiv. Bd. 239. 


\section{H. Schuppisser: Über Eiseninkrustation der Bindegewebssubstanzen}

In der Ablagerung der Eisenkonkremente möchten wir einen analogen Vorgang erblicken, wie ihn die Ablagerung von harnsauren Salzen in die kollagene Substanz bei der Gicht darstellt. (Vereinzelt wurde allerdings bei letzterer auch eine Ablagerung von Krystallen in den Knorpelzellen beobachtet. Siehe bei $M . B$. Schmidt.) Thre Ursache besteht in der Úberladung der Gewebsflüssigkeiten mit Harnsäure und ihren Salzen. Auch die Kalkablagerungen, die im Gefolge von Kalkmetastasen im Sinne Virchows auftreten, stellen in gewissem Sinne ein Analogon zu unseren Eisenablagerungen dar, indem die dort auftretenden Verkalkungen ebenfalls auf einer Überladung des Blutserums mit einem zur Ausscheidung ins Bindegewebe neigenden Stoffe, eben mit Calcium, beruhen. Hier betrifft, wie bei der Gicht, diese Überladung das Blut und sämtliche Gewebsflüssigkeiten, doch kommen bei der Kalkmetastase für die Ausscheidung des Kalkes noch besondere lokale Bedingungen, nämlich die relative Säurearmut der Gewebe, in welchen die Ablagerungen stattfinden, in Betracht. Näher verwandt mit den Vorgängen in unseren Strumen und in der Milz ist die sog. lokale Kalkmetastase, deren Begriff von $M . B$. Schmidt aufgestellt wurde. Hier besteht nicht eine generelle Überladung des Serums mit Calcium, sondern diese ist auf gewisse Organgebiete beschränkt und führt in deren Bereiche zur Kalkausscheidung. In diesem Sinne faßt er die häufig beobachteten Verkalkungen in der Dura mater bei Kalkschwund des Schädels auf, wobei das in vermehrtem Maße mit dem Saftstrom der Dura zugeführte Calcium in den kollagenen Fasern derselben niedergeschlagen wird.

Endlich verdient noch die in unserer Milz vorgefundene Eiseninkrustation elastischer Fasern besondere Erwähnung. Sehr bemerkenswert ist, daß in einigen Herden eine Eisenaufnahme sowohl in der kollagenen als auch in der elastischen Substanz stattgefunden hat, wobei aber das eisenhaltige, elastische Faserwerk gut von den kollagenen Fibrillen zu unterscheiden ist. In der Milzkapsel, wo in den Blutungsherden die Eisenaufnahme fast ausschließlich in den elastischen Fasern erfolgt ist, kommt es zum Sichtbarwerden eines zarten Gitterwerkes, das in vielem an das oben in den Lymphdrüsen beschriebene erinnert. Vereinzelt kommt es nämlich auch hier zu einem Durchsichtigwerden der eisenhaltigen, elastischen Fasern, zugleich zu einer verhältnismäßig starken Verdickung. Hervorzuheben ist an diesen Stellen noch der Befund von Riesenzellen. Auf die besondere Neigung von elastischen Fasern lebender Gewebe, sich in der Nachbarschaft von Hämorrhagien mit eisenhaltigen Verbindungen zu beladen, hat Ehrlich hingewiesen. Sie kommt auch in unserer Milz in prägnanter Weise zum Ausdruck. Die Inkrustation der Elastica interna von Gefässen bezeichnet Ehrlich als Siderosis elasticae internae. 
Die in der Literatur erschienenen Angaben über Eisenablagerungen, in denen nicht zugleich von der Beziehung zu Verkalkungen die Rede ist, sind, wie eingangs erwähnt, recht spärlich. So berichtet Marchand über eigentümliche Pigmentkrystalle in den Lungen in zwei Fällen von akutem Stauungszustand infolge Insuffizienz der Herztätigkeit. Diese Krystalle liegen meist in den Alveolen und sind stäbchenförmig, zum Teil auch fadenförmig und an den Enden oft nagelkopfartig verdickt, zum Teil auch durch quere, farblose Iinien zergliedert. Ihre Farbe ist hellgelb-rötlichgelb. Sie geben intensive Fe-reaktion, sind nicht doppelbrechend, unlöslich in Alkohol, Äther, Säuren und Alkalien. Marchand hält es für wạhrscheinlich, daß es sich um Krystallisation des eisenhaltigen Pigments mit einem myelinartigen Produkt der Epithelzellen handelt. Buday sah bei Lungengangrän und foetider Bronchitis bräunliche, längliche Fäden bildende, zum Teil unregelmäßig verdickte Krystalle mit starkem Eisengehalt, die er mit den von Marchand beschriebenen für identisch hält. Neuerdings beschreibt Nissen in einer Lunge eigentümliche eisenhaltige Myelinmassen, die sich mit Hämatoxylin blau färben, und deren äußere Gestalt kuchenteigartig wechselnde Formen zeigt. Sie enthalten zentral oft farblose, doppelbrechende Kristalle. Oberndorfer berichtet über tropfenund wurmförmige, doppelbrechende Gebilde von brauner Farbe mit starkem Eisengehalt in einer Milz bei Bantischer Krankheit. Alle diese Formen von Eisenablagerung haben das Gemeinsame, daß die Eisenabscheidung hier in myelinartigen Substanzen erfolgte. Hieraus ergibt sich schon der große Unterschied gegenüber meinen Befunden, denn bei letzteren bildet die kollagene Substanz das Substrat für die Eisenkonkretionen. Viel größere Verwandtschaft mit unseren Konkrementen haben die von Bittrolf in einer Stauungslunge beschriebenen, eigentümlichen grünlichen, durchsichtigen Fäden und größeren klumpigen Gebilde, die in ihrem Aussehen mit unseren Konkrementen viel Gemeinsames haben, sich aber von ihnen in chemischer Beziehung sowie dadurch unterscheiden, daß sie sich als veränderte elastische Fasern erweisen. Bittrolf hält sie für kalk- und eisenhaltig; nach einer späteren vonGigon ausgeführtenUntersuchung ist jedoch statt desCalciumsNatrium und Kalium vorhanden. Die hier angeführten Veränderungen der Gefäßwände erinnern ganz an die von uns beschriebenen, da die umgewandelten elastischen Fasern ebenfalls in konzentrischer Anordnung vorkommen. In unseren Strumen kann es sich aber bei den Gefäßen nur um eine Inkrustation der kollagenen Substanz handeln, da in Strumen in kleinen und mittelgroßen Gefäßen elastische Elemente nicht nachgewiesen werden können. Unsere Elastinfärbungen ergaben denn auch immer ein negatives Resultat. Hingegen habe ich in der Milz, wie oben erwähnt, die Eiseninkrustation von elastischen Fasern in den Gefäßen festgestellt. 
Die von Aschoff erwähnten eisenhaltigen Krystalle, die er in einem leukämischen Milztumor beobachtete und bei welchen er teilweise einen Übergang in die Fasern des Reticulums feststellen konnte, sind wahrscheinlich mit unseren in der Milz beschriebenen Konkrementen identisch.

Nach Abschluß meiner Untersuchungen erschien die Arbeit von Kraus, in welcher genau die gleichen eisenhaltigen Konkremente beschrieben sind, wie ich sie gesehen habe. Kraus fand sie in einer Milz bei einem Falle von lymphatischer Leukämie, und zwar nach Röntgenbestrahlung, was also mit meiner Beobachtung übereinstimmen würde. Leider konnte ich die Kraus schen Ergebnisse bei meinen Untersuchungen nicht mehr genau berücksichtigen. Kraus hält die Konkremente für Eisenphosphat, $d a$ er mit Salpetersäure und molybdänsaurem Ammon eine positive Reaktion erhielt. Die Reaktion auf Phosphorsäure habe ich nachträglich an den Konkrementen in meinen Strumen ebenfalls ausgeführt und erhielt, wenigstens an zahlreichen Konkrementen, positive Ergebnisse. Danach enthalten sie also zum Teil Phosphorsäure, die wahrscheinlich mit dem Eisen eine Bindung eingegangen ist. Da die Reaktion aber lange nicht an allen Konkrementen auftritt, so kann ich meine Auffassung nicht fallen lassen, daß es sich dabei auch um Eisenhydroxyd handelt. Die Meinung von Kraus, daß vielleicht bloß die Milz zur Bildung dieser Konkremente befähigt sei, wird durch meine Beobachtungen widerlegt.

$\mathrm{Zu}$ Schluße möchte ich noch anführen, daß die hier beschriebenen eisenhaltigen Konkremente keineswegs so selten auftreten, wie dies nach den äußerst dürftigen Angaben in der Literatur zu sein scheint. Herr Prof. Wegelin konnte sie zu verschiedenen Malen in Strumaknoten und in der Milz beobachten, wenn auch in keinem Falle in so reichlichem Maße wie in den hier beschriebenen Fällen.

Zusammengefaßt ergeben meine Untersuchungen folgendes:

1. Eine eigenartige, selektive Inkrustation der Gitterfasern mit Eisen in den retroperitonealen Lymphdrüsen bei einem Falle von allgemeiner Hämochromatose, wobei es in den inkrustierten Fasern teilweise auch zu einer nachträglichen Kalkaufnahme gekommen ist.

2. In zwei Fällen von Struma nodosa und in einer lymphogranulomatösen Milz eine eigentümliche Ablagerung von Eisen in Form von Konkrementen. Als Substrat dieser Ablagerungen ist die kollagene Substanz zu betrachten. Chemisch handelt es sich dabei um Eisenoxydhydrat und um Eisenphosphat.

3. Eine Bestätigung der starken Affinität der elastischen Sub$\operatorname{stanz}$ zu Eisen.

\section{Literaturverzeichnis.}

Anschiitz, Über Diabetes mit Bronzefärbung der Haut. Dtsch. Arch. f. klin. Med. 62. 1899. - Aschoff, Siehe unter Marchand. - Best, Über mikroskopische 
Eisenreaktion. Verh. d. dtsch. pathol. Ges., \%. 1904. - Bittrolf, Über kalk- u. eisenhaltige elastische Fasern in den Lungen. Beitr. z. pathol. Anat. u. z. allg. Pathol. 49. 1910. - Buday, Histologische Untersuchungen über die Entstehungsweise der Lungengangrän. Beitr. z. pathol. Anat. u. z. allg. Pathol. 48. 1910. Ehrlich, Eisen- und Kalkimprägnation in menschlichen Geweben, insbesondere der elastischen Fasern. Zentralbl. f. allg. Pathol. u. pathol. Anat. 17. 1906. Eliascheff, Gibt es einen intravitalen Eisengehalt verkalkter Gewebe? Beitr. z. path. Anat. u. z. allg. Pathol. 50. 1911. - Gierke, Über Eisengehalt verkalkter Gewebe. Virchows Arch. f. pathol. Anat. u. Physiol. 16\%. 1902. - Gigon, Eisen- und Alkaliimprägnation des Lungengewebes. Beitr. z. pathol. Anat. u. z. allg. Pathol. 55. 1913. - Hueck, Über den angeblichen Eisengehalt verkalkter Gewebe. Arbeiten aus dem Pathol.-Anat. Institut zu Tübingen 6. 1908. - Hueck, Die pathologische Pigmentierung. Handb. d. allg. Pathol. von Krehl u. Marchand. 3 2. 1921. Kockel, Über die Kalkinkrustationen des Lungengewebes. Dtsch. Arch. f. klin. Med. Bd. 64. 1899. - Kraus, Über ein bisher unbekanntes eisenhaltiges Pigment in der menschlichen Milz. Beitr. z. pathol. Anat. u. allg. Pathol. ro, 1922.

Lubarsch, Zur Entstehung der Gelbsucht. Berl. klin. Wochenschr. 1921, Nr. 28. Lubarsch, Zur Kenntnis des makrophagen (reticulo-endothelialen) Systems. Verh. d. dtsch. pathol. Ges. 18. 1921. - Marchand, Über eigentümliche Pigmentkrystalle in den Lungen. Verh. d. dtsch. pathol. Ges., 10. 1906. - Nissen, Ửber eigentümliche eisenhaltige Myelinmassen in der Lunge. Beitr. z. pathol. Anat. u. z. allg. Pathol. 70. 1922. - Noesske, Über Vorkommen und Bedeutung von Eisen in verkalkten Geweben, insbesondere den Knochen. Zentralbl. f. allg. Pathol. u. pathol. Anat. 20. 1909. - Oberndorfer, Siehe unter Marchand. - Orth, Siehe unter Hueck in Arbeiten aus dem Pathol.-Anat. Institut zu Tübingen. 6. 1908. - Rössle, Über Phagocytose von Blutkörperchen durch Parenchymzellen und ihre Beziehung zum hämorrhagischen Ödem und zur Hämochromatose. Beitr. z. pathol. Anat. u. z. allg. Pathol. 41. 1907. - Schmidt, M. B., Die Verkalkung. Handb. d. allg. Pathol. von Krehl u. Marchand. 3. 1921. - Schmidt, M. B., Ablagerung harnsaurer Salze. Handb. f. allg. Pathol. von Krehl u. Marchand 3. 2. 1921. - Schmorl, Über feine Knochenstrukturen und über den Eisengehalt des Knochengewebes unter pathologischen Verhältnissen. Verh. d. dtsch. pathol. Ges. 6. 1903. — Sträter, Beiträge zur Lehre von der Hämochromatose und ihren Beziehungen zur allgemeinen Hämosiderose. Virchows Arch. f. pathol. Anat. u. Physiol. 218. 1914. - Stoelzner, Über Metallfärbungen verkalkter Gewebe. Virchows Arch. f. pathol. Anat. u. Physiol. 180. 1905. - Sumita, Zhr Frage der Eisenreaktion kalkhaltiger Gewebe. Virchows Arch. f. pathol. Anat. u. Physiol. 200. 1910. - Ungeheuer, Ein Fall von Bronzediabetes mit besonderer Berücksichtigung des Pigmentes. Virchows Arch. f. pathol. Anat. u. Physiol. 216. 1914. - Wegelin, Über das Stroma der normalen und pathologischen Schilddrüse. Frankf. Zeitschr. f. Pathol. 4. 1910. 